\title{
Detection of Energy Theft in Overhead Low-Voltage Power Grids - The Hook Style Energy Theft in the Smart Grid Era
}

\author{
Athanasios G. Lazaropoulos* \\ School of Electrical and Computer Engineering / National Technical University of Athens / \\ 9 Iroon Polytechniou Street / Zografou, GR 15780
}

Received August 24, 2018; Accepted October 20, 2018; Published October 26, 2018

\begin{abstract}
This paper investigates the possibility of detecting the hook style energy theft in the overhead low-voltage (OV LV) power grids when the smart grid conveniences are available. On the basis of the broadband over power lines (BPL) technology and the proposed method of the detection of the hook style energy theft (HS-DET method), a plethora of different scenarios concerning the hook style energy theft is considered so that the performance of HS-DET method can be assessed. The impact of OV LV BPL topologies, hook characteristics and measurement differences on the performance of HS-DET method is mainly assessed through appropriate metrics, such as derivative metrics of percent error sum (PES). Finally, appropriate contour plots against the hook style energy theft are proposed revealing the efficiency of HS-DET method against any relevant threat in any conditions.
\end{abstract}

Keywords: Smart Grid; Broadband over Power Lines (BPL); Power Line Communications (PLC); Distribution Power Grid; Energy Theft.

\section{Introduction}

Energy theft defines a well-known problem either in traditional power systems or in the emerging smart grid [1]-[7]. In fact, a World Bank report indicates that up to 50\% of electricity in developing countries is acquired via energy theft [8] while, in financial terms, utility companies have announced losses that reach up to $\$ 6$ billion, $\$ 5$ billion and $\$ 4.5$ billion in United States, Brazil and India, respectively [9]-[11]. To cope with the energy theft, a plethora of detection schemes have been proposed in the literature, on behalf of the states and power utility companies, that exploit smart meters, wireless sensors and radio-frequency identification tags in order to provide a high detection accuracy. However, the main disadvantage of these detection schemes is the required extra investment cost that includes the device cost, the system implementation cost, the software cost and the operating/training cost [3], [12]-[15]. Also, compared to the traditional power grid, which can only be physically tampered, the smart grid is vulnerable to more types of attacks (e.g., network attacks) [4].

On the basis of suitable broadband applications, such as this one that is presented in this paper, the interoperability of the smart grid with the broadband over power lines 
(BPL) systems can offer significant help towards the combat against the energy theft and finally restore the financial losses of the power utility companies due to this issue. Here, it should be highlighted that among the available communications technologies that can interoperate under the aegis of the smart grid, the BPL technology can play the crucial role during the detection of the energy theft since the BPL technology exploits the already installed power grid infrastructure [16]-[18].

In this paper, the detection of the hook style energy theft of the overhead low-voltage (OV LV) power grids, which is a common type of energy theft in developing countries, is here analyzed on the basis of the installed BPL networks and the hybrid model [19]-[36]. Until now, hybrid model has extensively been employed to examine the behavior of various multiconductor transmission line (MTL) configurations in transmission and distribution BPL networks and, of course, in OV LV BPL networks such those that are examined in this paper. Actually, the hybrid model consists of two interconnected modules, namely: (i) the bottom-up approach module that is based on an appropriate combination of MTL theory and similarity transformations; and (ii) the top-down approach module that is based on the concatenation of multidimensional transmission matrices of the cascaded network BPL connections. On the basis of broadband performance metrics supported by the hybrid method such as channel attenuation, spectral efficiency and capacity, a number of BPL broadband applications, such as Topology Identification Methodology (TIM) [37], Fault and Instability Identification Methodology (FIIM) [38], methodology to preserve power system stability [39], [40] and main line fault localization methodology (MLFLM) [41]-[43], have already been demonstrated. In this paper, the hook style energy theft detection method (HS-DET method) is proposed and aims at coping with the detection of hook style energy theft in OV LV BPL networks.

The proposed HS-DET method is investigated either in theoretical or in real operation conditions of OV LV BPL networks. Already been mentioned in [37]-[39], [41]-[44], measurement differences between the real results collected by in-situ measurements and the theoretical results derived from the hybrid model occur during the channel attenuation determination that further affect the computation of the broadband performance metrics. In accordance with [37]-[39], [42], [45], [46], to deal with the measurement differences, the measurement differences can comfortably be handled as error distributions such as continuous uniform distributions (CUDs). Anyway, HS-DET method adopts the metric of percent error sum (PES), which has extensively applied in the aforementioned BPL broadband applications, as its main performance metric in order to assess the power grid integrity and allow the detection of energy theft.

The rest of this paper is organized as follows: In Section 2, a brief synopsis of MTL configurations of OV LV power grids, indicative OV LV BPL topologies, signal transmission and signal coupling is given. Section 3 deals with the measurement differences as well as PES and HS-DET method. In Section 4, numerical results and discussion are provided, aiming at practically evaluating the possibility of detecting a hook style energy theft and assess the detection performance of HS-DET method when measurement differences occur and hook style energy theft exists. Section 5 concludes this paper. 


\section{OV LV BPL Network Synopsis}

\subsection{OV LV MTL Configuration}

A typical case of an OV LV distribution line is depicted in Fig. 1. Overhead distribution lines hang above the ground. OV LV distribution lines consist of three parallel non-insulated phase conductors of radius $r_{\mathrm{p}}^{\mathrm{OVLV}}$ while the lowest phase conductor is hung at height $h^{\mathrm{OVLV}}$ above the ground. Above the three phase conductors, there is a neutral conductor of radius $r_{\mathrm{n}}^{\mathrm{OVLV}}$. The vertical spacing of the four conductors is equal to $\Delta^{\mathrm{OVLV}}$. More details regarding the material properties and dimensions of OV LV MTL configurations are given in [19].

As the ground properties are concerned, the ground is considered as the reference conductor while its conductivity and relative permittivity are assumed to be equal to $\sigma_{\mathrm{g}}=5 \mathrm{mS} / \mathrm{m}$ and $\varepsilon_{\mathrm{rg}}=13$, respectively [19], [21], [22], [25], [27]-[29]. The consideration of an imperfect ground defines a realistic scenario whose impact on high frequency signal propagation and transmission through OV LV power lines is detailed in [19]-[25], [27]-[29], [47]-[52].

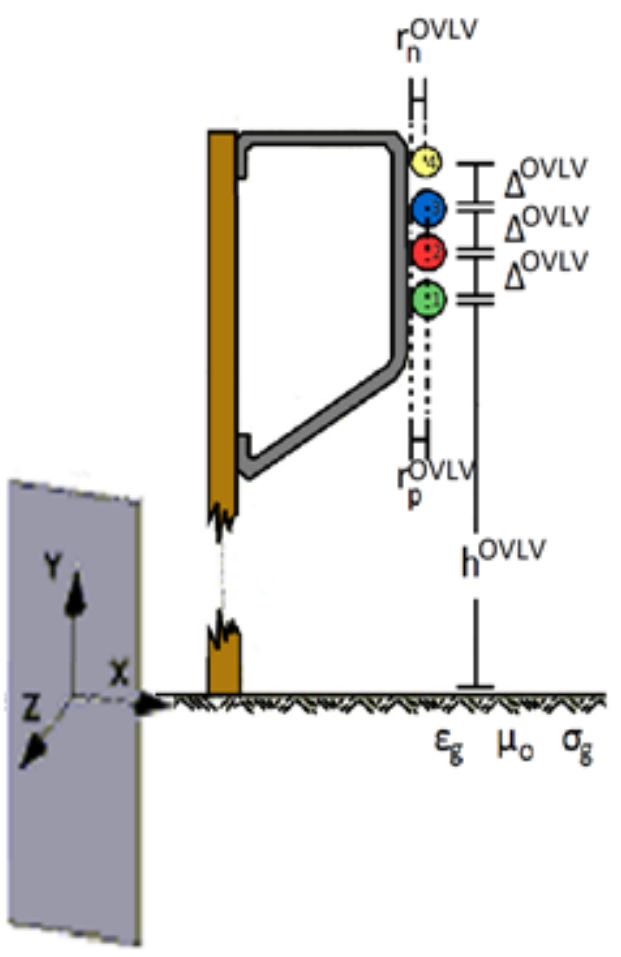

Fig. 1. Typical OV LV MTL configurations [19].

\subsection{Indicative OV LV BPL Topologies and Hook Insertion Impact}

In accordance with [1], [37]-[43], [53], BPL networks constitute a feedback loop control system that relies on measurement data that are collected by BPL units, meters and sensors, which are deployed across the power lines as well as their surrounding environment. In fact, BPL networks are divided into cascaded BPL connections, which can be treated separately. Each BPL connection is bounded by the transmitting end and 
receiving end repeaters that allow the amplification and regeneration of the attenuated BPL signals. Between the transmitting and receiving end of a BPL connection, the number of branches as well as the topological characteristics may vary depending on the type of the supported power grid. On the basis of its topological characteristics, each BPL connection can be treated as a different OV LV BPL topology. In Fig. 2(a), a typical BPL topology with $N$ branches is shown. With respect to Fig. 2(a), one of the main inputs of the hybrid model is the topological profile of the examined OV LV BPL topology. In Table 1, the topological characteristics of indicative OV LV BPL topologies are reported.

a)

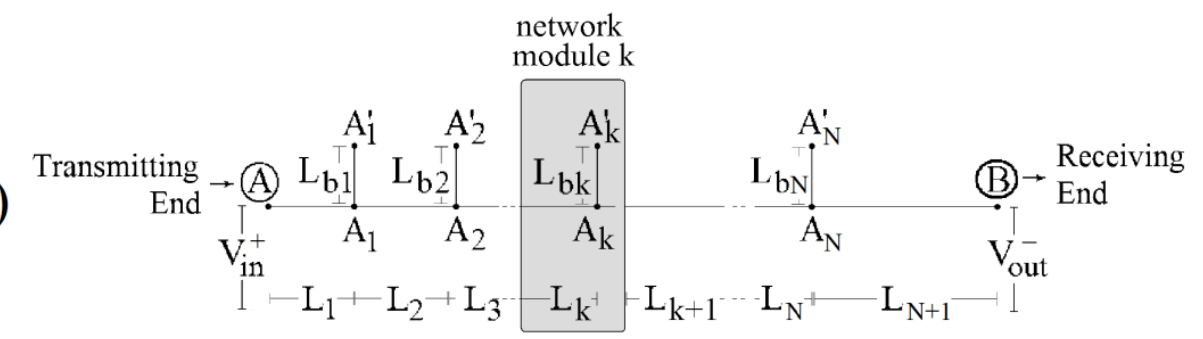

b)

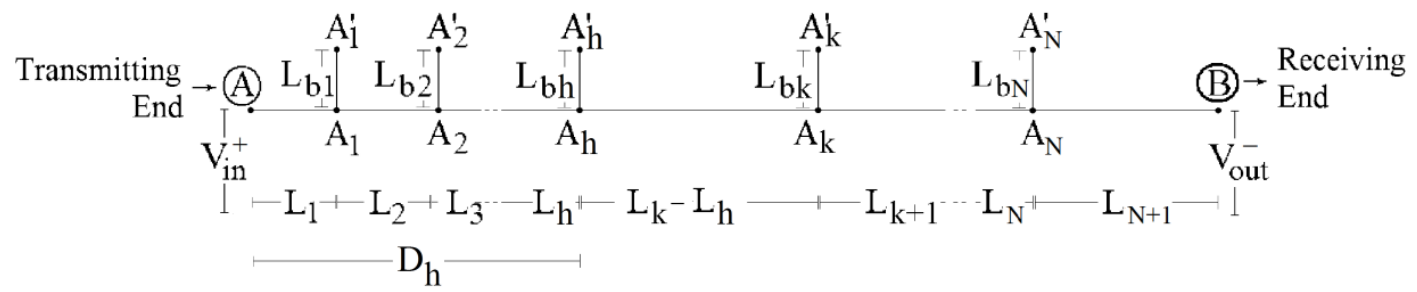

Fig. 2. (a) Original end-to-end OV LV BPL topology with $N$ branches [19], [54], [55]. (b) Modified end-to-end OV LV BPL topology due to the hook insertion.

Table 1. Indicative OV LV BPL Topologies [46]

\begin{tabular}{|c|c|c|c|c|}
\hline $\begin{array}{c}\text { Topology } \\
\text { Name }\end{array}$ & Topology Description & $\begin{array}{c}\text { Number of } \\
\text { Branches }\end{array}$ & $\begin{array}{c}\text { Length of } \\
\text { Distribution Lines }\end{array}$ & $\begin{array}{c}\text { Length of } \\
\text { Branching Lines }\end{array}$ \\
\hline Urban case A & Typical OV urban topology & 3 & $\begin{array}{c}\mathrm{L}_{1}=500 \mathrm{~m}, \\
\mathrm{~L}_{2}=200 \mathrm{~m}, \\
\mathrm{~L}_{3}=100 \mathrm{~m}, \mathrm{~L}_{4}=200 \mathrm{~m}\end{array}$ & $\begin{array}{c}\mathrm{L}_{\mathrm{b} 1}=8 \mathrm{~m}, \mathrm{~L}_{\mathrm{b} 2}=13 \mathrm{~m}, \\
\mathrm{~L}_{\mathrm{b} 3}=10 \mathrm{~m}\end{array}$ \\
\hline Urban case B & $\begin{array}{c}\text { Aggravated OV urban } \\
\text { topology }\end{array}$ & 5 & $\begin{array}{c}\mathrm{L}_{1}=200 \mathrm{~m}, \mathrm{~L}_{2}=50 \mathrm{~m}, \\
\mathrm{~L}_{3}=100 \mathrm{~m}, \\
\mathrm{~L}_{4}=200 \mathrm{~m}, \\
\mathrm{~L}_{5}=300 \mathrm{~m}, \mathrm{~L}_{6}=150 \mathrm{~m}\end{array}$ & $\begin{array}{c}\mathrm{L}_{\mathrm{b} 1}=12 \mathrm{~m}, \mathrm{~L}_{\mathrm{b} 2}=5 \mathrm{~m}, \\
\mathrm{~L}_{\mathrm{b} 3}=28 \mathrm{~m}, \mathrm{~L}_{\mathrm{b} 4}=41 \mathrm{~m}, \\
\mathrm{~L}_{\mathrm{b} 5}=17 \mathrm{~m}\end{array}$ \\
\hline Suburban case & OV suburban topology & 2 & $\begin{array}{c}\mathrm{L}_{1}=500 \mathrm{~m}, \\
\mathrm{~L}_{2}=400 \mathrm{~m}, \mathrm{~L}_{3}=100 \mathrm{~m}\end{array}$ & $\mathrm{~L}_{\mathrm{b} 1}=50 \mathrm{~m}, \mathrm{~L}_{\mathrm{b} 2}=10 \mathrm{~m}$ \\
\hline Rural case & OV rural topology & 1 & $\mathrm{~L}_{1}=600 \mathrm{~m}, \mathrm{~L}_{2}=400 \mathrm{~m}$ & $\mathrm{~L}_{\mathrm{b} 1}=300 \mathrm{~m}$ \\
\hline "LOS" case & OV Line-of-Sight & 0 & $\mathrm{~L}_{1}=1000 \mathrm{~m}$ & - \\
\hline
\end{tabular}


Since the HS-DET method in OV LV power grids is examined in this paper, a hook insertion modifies the examined indicative OV LV BPL topologies of Table 1 as indicated in Fig. 2(b). Let assume that a hook is hung at the position $A_{h}$ that is located at distance $D_{\mathrm{h}}=L_{\mathrm{h}}+\sum_{i=1}^{k-1}\left(L_{i}\right)$ from the transmitting end. Hence, the distance between the hook and the $k$ th branch is equal to $L_{k}-L_{\mathrm{h}}$. The length of the hook, which is treated as a branch from the hybrid model, is assumed to be equal to $L_{\mathrm{bh}}$. From Fig. 2(b), it is evident that each examined indicative OV LV BPL topology is modified depending on the hook location and the hook length.

Apart from the topological characteristics of Table 1, a set of assumptions concerning the transmission and propagation of the BPL signal as well as the circuital characteristics of the OV LV MTL configurations have been detailed in [19]-[27], [29], [31], [56]-[60]. Except for the aforementioned assumptions, the hook termination is assumed to be open circuit while the hook interconnection with the distribution lines is assumed to be complete (i.e., hook derivation points at the same distance from the transmitting end on all the three phases) and horizontal. Therefore, the hook can be treated by the hybrid model as a branch. The previous assumptions are made in order to simplify the following analysis.

\subsection{BPL Signal Transmission and Coupling}

Hybrid method that deals with the BPL signal propagation and transmission across MTL configurations of OV LV BPL networks gives as output the $n^{\mathrm{G}} \times n^{\mathrm{G}}$ channel transfer function matrix $\mathbf{H}\{\cdot\}$ that relates line voltages $\mathbf{V}(z)=\left[\begin{array}{llll}V_{1}(z) & \cdots & V_{n^{\mathrm{G}}}(z)\end{array}\right]^{\mathrm{T}}$ at the transmitting $(z=0)$ and the receiving $(z=L)$ ends where $n^{\mathrm{G}}$ is the number of the conductors of the examined MTL configuration and []$^{\mathrm{T}}$ denotes the transpose of a matrix. Then, according to how signals are injected onto and extracted from the lines of OV LV BPL networks, different coupling schemes may occur [19], [22], [25], [27]-[29], [54], [55]. In [54], [55], CS2 module has been introduced and is adopted in this paper. In accordance with [54], [55] where a number of restrictions is detailed, the coupling scheme channel transfer function of a coupling scheme module that relates output BPL signal $V^{\text {out- }}$ and input BPL signal $V^{\text {in }+}$ is given by

$$
H^{\mathrm{c}}\{\cdot\}=\frac{\left[V^{\text {out }-}\right]^{\mathrm{C}}}{\left[V^{\text {in }+}\right]^{\mathrm{C}}}=\left[\mathbf{C}^{\text {out }}\right]^{\mathrm{C}} \cdot \mathbf{H}\{\cdot\} \cdot\left[\mathbf{C}^{\text {in }}\right]^{\mathrm{C}}
$$

where $\mathbf{C}^{\text {in }}$ is the input coupling vector, $\mathbf{C}^{\text {out }}$ is the output coupling vector and []$^{\mathrm{c}}$ denotes the applied coupling scheme. With reference to [54], [55] and eq. (1), three types of coupling schemes can be supported: (i) Coupling Scheme Type 1: Wire-to-Ground (WtG) or Shield-to-Phase (StP) coupling schemes; (ii) Coupling Scheme Type 2: Wire-to-Wire $(W t W)$ or Phase-to-Phase (PtP) coupling schemes, and (iii) Coupling Scheme Type 3: MultiWire-to-MultiWire (MtM) or MultiPhase-to-MultiPhase (MtM) coupling schemes. Depending on the applied coupling scheme, $\mathbf{C}^{\text {in }}$ and $\mathbf{C}^{\text {out }}$ are properly defined and, then, the coupling scheme channel transfer function $H^{\mathrm{c}}\{\cdot\}$ is straightforward computed. Apart from the applied coupling scheme, the coupling scheme channel transfer function depends on the frequency, the OV LV BPL topology, the physical properties of the cables and the geometry of the MTL configuration [19], [21], [46], [58], [61]. 


\section{Measurement Differences, PES and HS-DET}

\subsection{Measurement Differences}

Although the theoretical computation of the coupling scheme channel transfer function, as described in eq. (1), is a well-defined straightforward process and, at the same time, experimentally verified, a set of practical reasons and "real-life" conditions can create significant differences between experimental measurements and theoretical results. These differences are denoted as measurement differences while the causes of the measurement differences can be grouped into six categories [37], [41], [44]. In mathematical terms, the measured coupling scheme transfer function $\overline{H^{\mathrm{C}}}\{\cdot\}$ for given coupling scheme can be determined by

$$
\overline{H^{\mathrm{C}}}\left(f_{i}\right)=H^{\mathrm{C}}\left(f_{i}\right)+e\left(f_{i}\right), i=1, \ldots, u
$$

where $f_{i}, i=1, \ldots, u$ denotes the measurement frequency, $e\left(f_{i}\right)$ synopsizes the total measurement difference in $\mathrm{dB}$ due to the six categories and $u$ is the number of subchannels in the examined frequency range. As it is usually done [41]-[44], the total measurement difference can be assumed to follow continuous uniform distribution (CUD) with minimum value $-a_{\text {CUD }}$ and maximum value $a_{\text {CUD }}$.

It is evident that the determination of the measured coupling scheme transfer function of original and modified end-to-end OV LV BPL topologies suffers from the same total measurement differences, and thus same CUD of measurement difference, for given MTL configuration, OV LV BPL topology and measurement equipment. With reference to eq. (2), $H_{\mathrm{or}}^{\mathrm{C}}\{\cdot\}$ and $H_{\text {mod }}^{\mathrm{C}}\{\cdot\}$ are the original and modified theoretical coupling scheme channel transfer functions, respectively, while $\overline{H_{\text {or }}^{\mathrm{C}}}\{\cdot\}$ and $\overline{H_{\text {mod }}^{\mathrm{C}}}\{\cdot\}$ are the original and modified measured coupling scheme channel transfer functions, respectively.

\subsection{PES}

As already been mentioned, a number of BPL broadband applications, such as TIM [37], FIIM [38], power system stability methodology [39], [40] and MLFLM [41]-[43], have already been demonstrated while their theoretical core is the cooperation of the hybrid model with the performance metric of percent error sum (PES). In accordance with [40], [44], PES assessed the approximation accuracy when piecewise monotonic data approximation methods have been applied in BPL networks. In this paper, PES is going to be employed so as to assess the approximation accuracy of the original and modified coupling scheme transfer functions. Therefore, PES expresses as a percentage of the total sum of the relative differences between the examined coupling scheme transfer function and the theoretical coupling scheme transfer function for all the used frequencies. With reference to eq. (5) of [46] and Sec. 3.1 of this paper, four PES metrics can be computed, namely:

$$
\begin{gathered}
P E S_{\mathrm{or}}=100 \% \cdot \frac{\sum_{i=1}^{u}\left|H_{\mathrm{or}}^{\mathrm{C}}\left(f_{i}\right)-H_{\mathrm{or}}^{\mathrm{C}}\left(f_{i}\right)\right|}{\sum_{i=1}^{u}\left|H_{\mathrm{or}}^{\mathrm{C}}\left(f_{i}\right)\right|}=0 \% \\
P E S_{\mathrm{mod}}=100 \% \cdot \frac{\sum_{i=1}^{u}\left|H_{\mathrm{mod}}^{\mathrm{C}}\left(f_{i}\right)-H_{\mathrm{or}}^{\mathrm{C}}\left(f_{i}\right)\right|}{\sum_{i=1}^{u}\left|H_{\mathrm{or}}^{\mathrm{C}}\left(f_{i}\right)\right|} \\
\overline{P E S_{\mathrm{or}}}=100 \% \cdot \frac{\sum_{i=1}^{u} \mid \frac{\left|H_{\mathrm{or}}^{\mathrm{C}}\left(f_{i}\right)-H_{\mathrm{or}}^{\mathrm{C}}\left(f_{i}\right)\right|}{\sum_{i=1}^{u}\left|H_{\mathrm{or}}^{\mathrm{C}}\left(f_{i}\right)\right|}}{\overline{P E S_{\mathrm{mod}}}}=100 \% \cdot \frac{\sum_{i=1}^{u}\left|H_{\mathrm{mod}}^{\mathrm{C}}\left(f_{i}\right)-H_{\mathrm{or}}^{\mathrm{C}}\left(f_{i}\right)\right|}{\sum_{i=1}^{u}\left|H_{\mathrm{or}}^{\mathrm{C}}\left(f_{i}\right)\right|}
\end{gathered}
$$


where $P E S_{\text {or }}, P E S_{\text {mod }}, \overline{P E S_{\text {or }}}$ and $\overline{P E S_{\text {mod }}}$ assess the accuracy of the original theoretical coupling scheme channel transfer function, modified theoretical coupling scheme channel transfer function, original measured coupling scheme channel transfer function and modified measured coupling scheme channel transfer functions, respectively, in relation with the original theoretical coupling scheme channel transfer function.

\subsection{HS-DET Method and $\triangle$ PES}

With reference to eqs. (3)-(6), HS-DET method of the OV LV power grids can detect energy theft whether measurement differences occur or not through the respective PES submetrics:

$$
\begin{gathered}
\overline{\Delta P E S}=\overline{P E S_{\mathrm{mod}}}-\overline{P E S_{\mathrm{or}}} \\
\triangle P E S=P E S_{\mathrm{mod}}-P E S_{\mathrm{or}}=P E S_{\mathrm{mod}}
\end{gathered}
$$

It is evident that when $\overline{\triangle P E S}$ and $\triangle P E S$ are greater than zero and all the other problematic cases of OV LV power grids are excluded (e.g., faults and instabilities of [37], [38], [62], [41], [42], [43]), a possible energy theft may occur across the OV LV power grid. This assertion is the theoretical basis of HS-DET method while the performance assessment of HS-DET method with respect to the existence of measurement differences or not is examined in the following Section of the numerical results.

\section{Numerical Results and Discussion}

The numerical results of this Section focus on the ability of HS-DET method to successfully detect the potential energy theft. Then, the performance of HS-DET method is assessed when various OV LV BPL topologies and types of hooks (i.e., different hook distances from the transmitting end and hook lengths) are assumed. Two main scenarios are examined, which are: (i) the absence of measurement differences; and (ii) the existence of different intensities of measurement differences.

\subsection{HS-DET Method without Measurement Differences}

The broadband performance, in terms of coupling scheme channel transfer function in the 3-88 MHz frequency band, is assessed by applying hybrid model and CS2 module when the indicative OV LV BPL topologies of Sec. 2.2 are considered. Also, one representative coupling scheme is considered in OV LV BPL topologies for the sake of simplicity; say, $\mathrm{WtG}^{1}$ coupling scheme.

With reference to Fig. 2(b), let assume that a hook of length $L_{\mathrm{bh}}$ is inserted at distance $D_{\mathrm{h}}$ from the transmitting end. In Table 2, PES ${ }_{\mathrm{or}}, P E S_{\mathrm{mod}}$ and $\triangle P E S$ are reported when $L_{\mathrm{bh}}=5 \mathrm{~m}$ and $D_{\mathrm{h}}=300 \mathrm{~m}$ are assumed for the five indicative OV LV BPL topologies.

\begin{tabular}{|c|c|c|c|}
\hline $\begin{array}{c}\text { OV LV BPL } \\
\text { Topology }\end{array}$ & $\begin{array}{c}P E S_{\text {or }} \\
(\%)\end{array}$ & $\begin{array}{c}P E S_{\text {mod }} \\
(\%)\end{array}$ & $\begin{array}{c}\triangle P E S \\
(\%)\end{array}$ \\
\hline Urban case A & 0 & 34.19 & 34.19 \\
\hline Urban case B & 0 & 28.17 & 28.17 \\
\hline Suburban case & 0 & 49.43 & 49.43 \\
\hline Rural case & 0 & 73.57 & 73.57 \\
\hline "LOS" case & 0 & 247.19 & 247.19 \\
\hline
\end{tabular}

Table 2. PES Metrics of Indicative OV LV BPL Topologies when $L_{\mathrm{bh}}=5 \mathrm{~m}$ and $D_{\mathrm{h}}=300 \mathrm{~m}$ 
From Table 2, as it was expected, $P E S_{\text {or }}$ is equal to zero while $P E S_{\bmod }$ assesses the asymmetry between the original and the modified OV LV BPL topology. In terms of $\triangle P E S$, the topology asymmetry after the hook insertion remains high when "LOS" LV BPL topology is examined since the almost stable behavior of coupling scheme transfer function of "LOS" case starts to obtain multipath characteristics, such as spectral notches, after the hook insertion. Conversely, low asymmetry through $\triangle \mathrm{PES}$ is reported in OV LV BPL topology of urban case B. In this case, the already intense multipath environment with its high number and deep spectral notches is rearranged through the hook insertion. The shift and the depth change of spectral notches of the modified OV LV BPL topology in comparison with ones of the original urban case B does not create the significant increase of $\triangle \mathrm{PES}$ already observed in the other OV LV BPL topologies, which is presented in Table 2. As for the other indicative OV LV BPL topologies, their $\triangle \mathrm{PES}$ behavior remains almost the same when a hook insertion occurs. However, $\triangle$ PES remains above $10 \%$ in all the cases examined.

HS-DET method should detect any hook presence regardless of its characteristics, say; its distance from the transmitting end and its length. However, due to the multipath environment of OV LV BPL networks, the performance of HS-DET method depends on the aforementioned hook characteristics. To investigate the performance of HS-DET method, in Fig. 3(a), $\triangle$ PES is plotted versus the hook distance from the transmitting end and the hook length when the OV LV BPL topology of urban case A is assumed. In Figs. 3(b), 3(c), 3(d) and 3(e), same plots with Fig. 3(a) are given but for the case of the urban case B, suburban case, rural case and "LOS" case, respectively. Here, it should be noted that the hook distance from the transmitting end span and the hook length span are assumed to be equal to $50 \mathrm{~m}$ and $5 \mathrm{~m}$, respectively, while the range of the hook distance from the transmitting end and the range of the hook length are from $1 \mathrm{~m}$ to $951 \mathrm{~m}$ and from $1 \mathrm{~m}$ to $46 \mathrm{~m}$, respectively, for all the examined contour plots of this paper. The selection of the previous plot specifications has been done for the sake of plot clarity and the computational speed. 


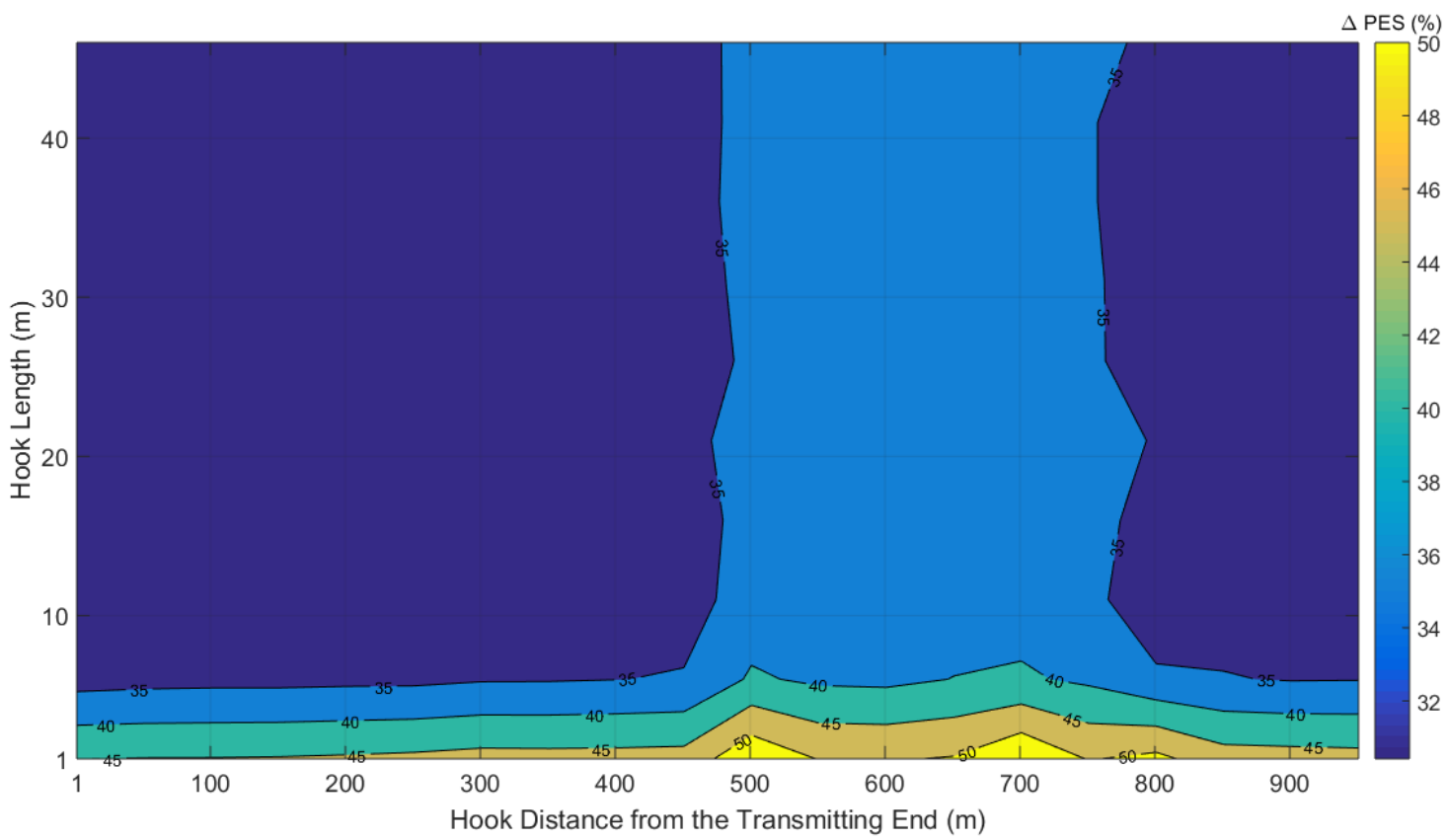

(a)

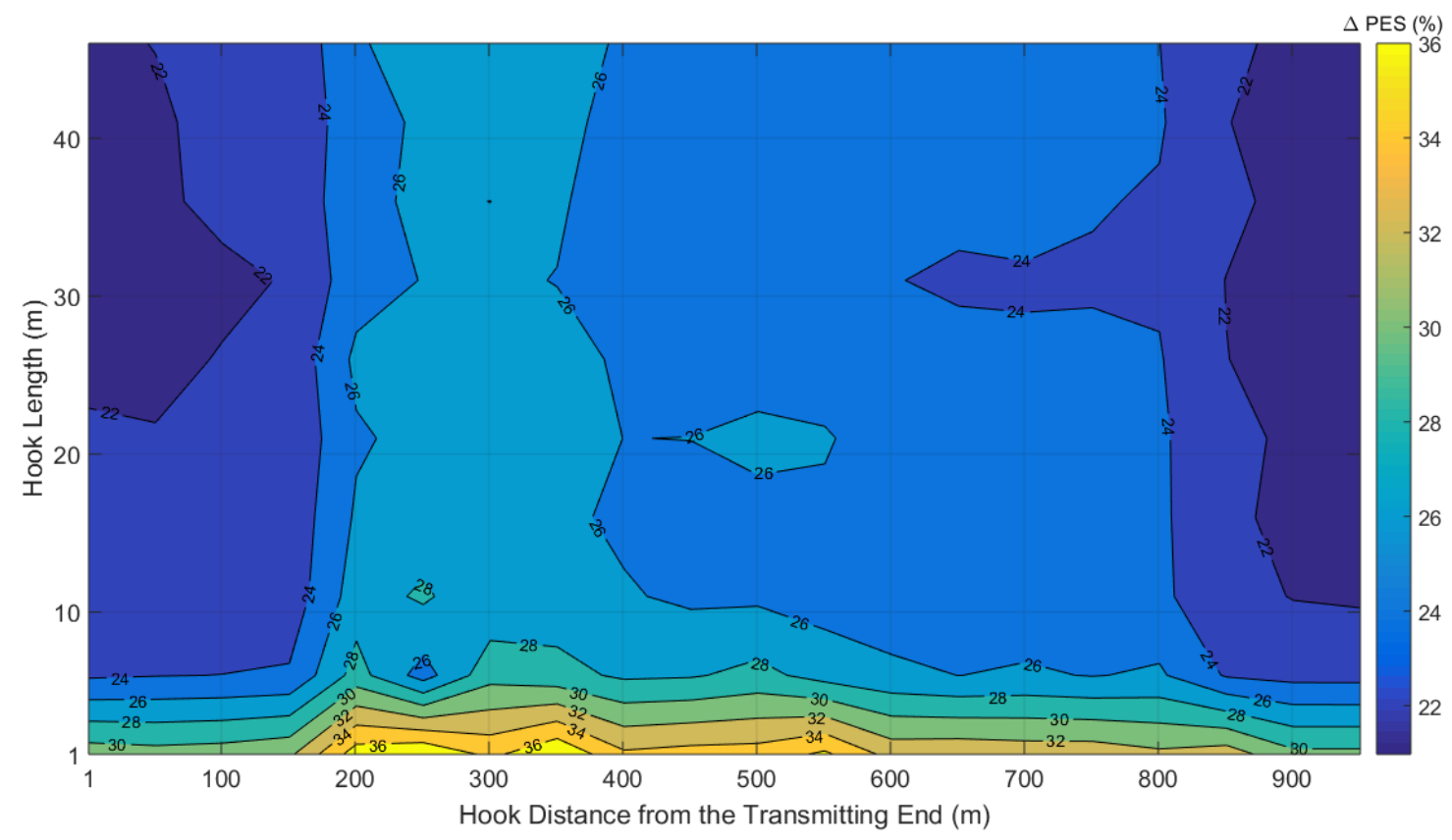

(b) 


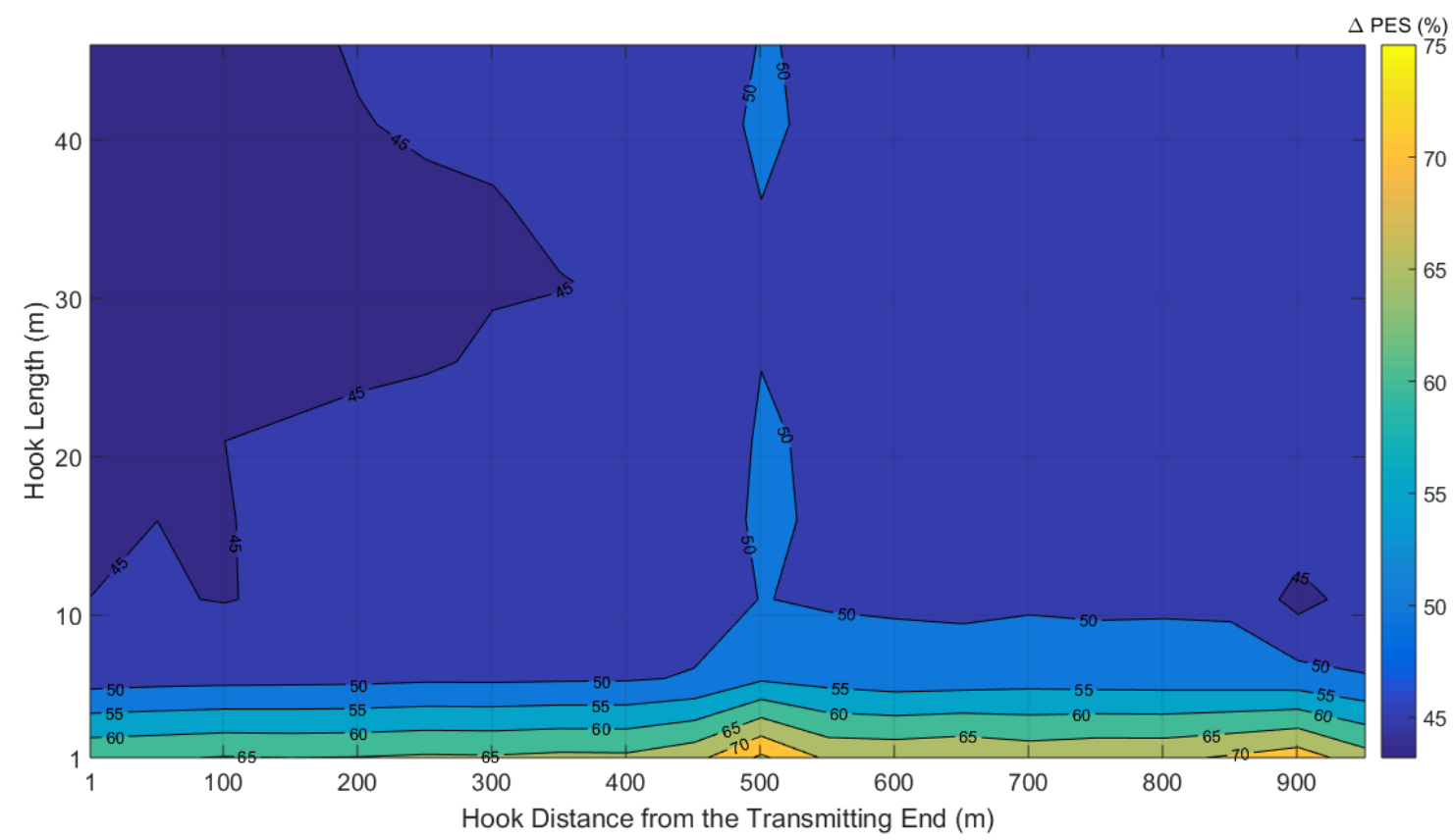

(c)

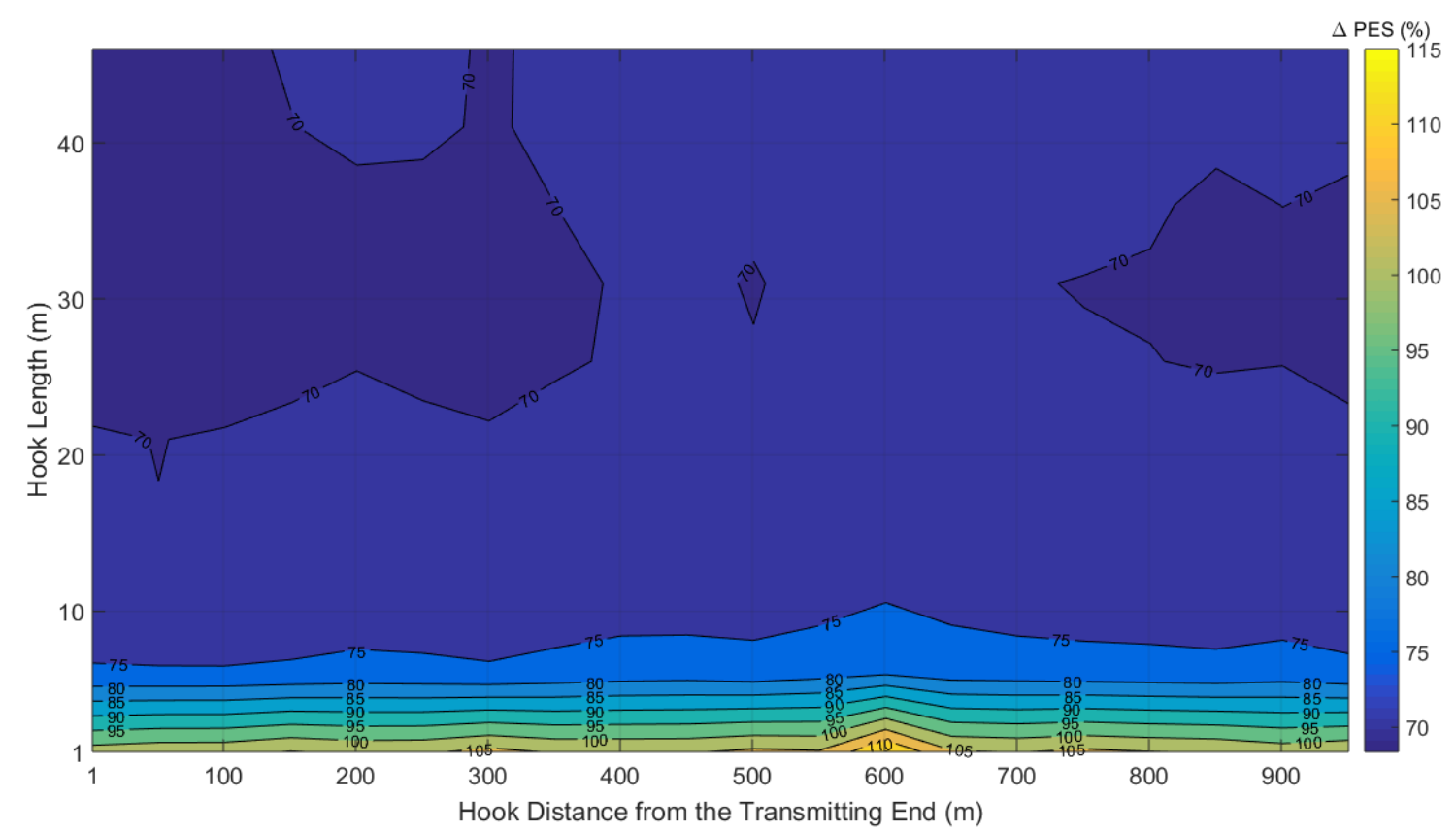

(d) 


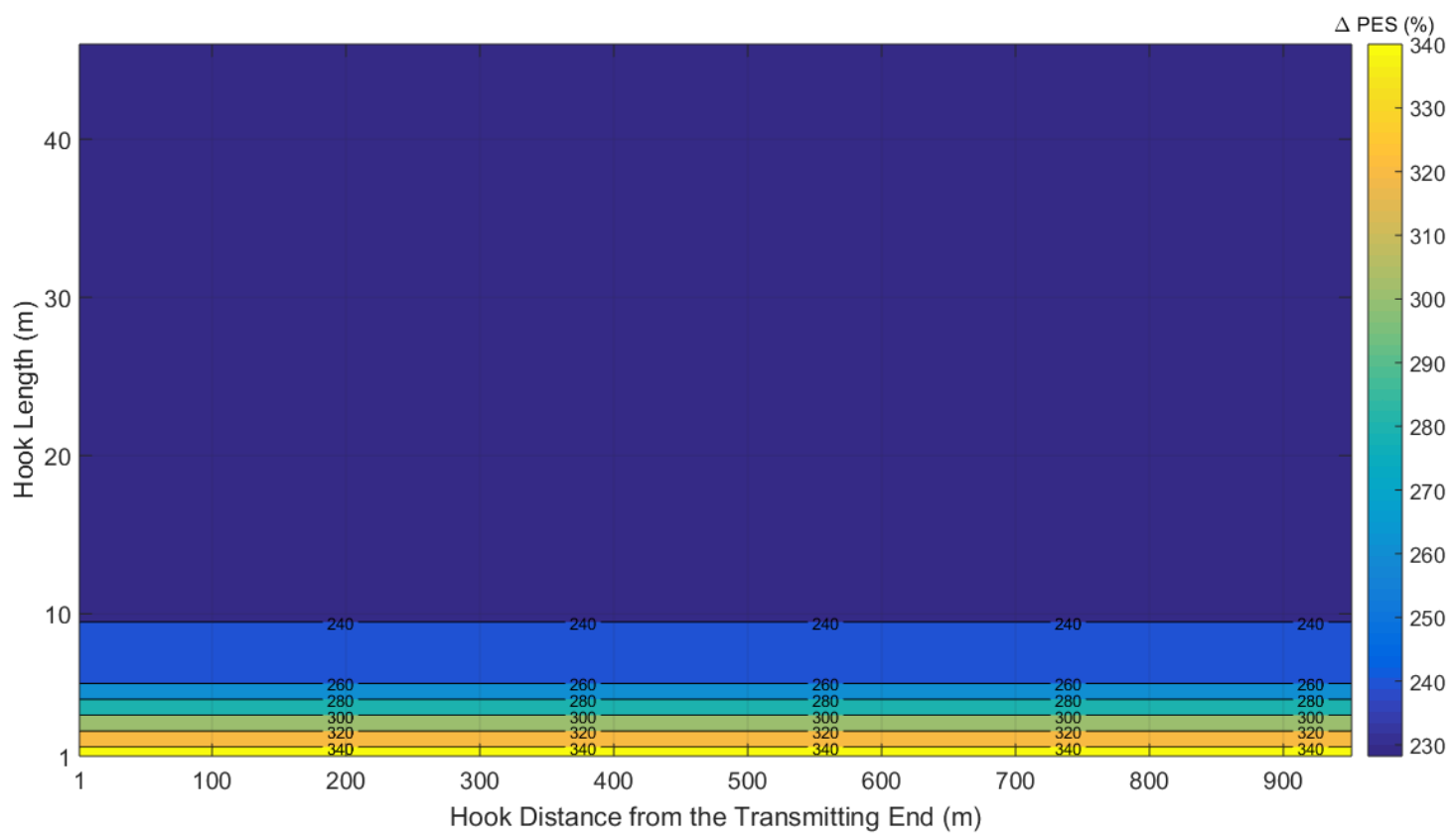

(e)

Fig. 3. $\triangle \mathrm{PES}$ of the indicative OV LV BPL topologies in the 3-88 MHz frequency band for various hook distances from the transmitting end and hook lengths. (a) Urban case A. (b) Urban case B. (c) Suburban case. (d) Rural case. (e) "LOS” case.

Figs. 3(a)-(e) validate the early observations from the Table 2, say:

- The hook detection becomes easier in the cases of OV LV BPL topologies of low number of long branches. "LOS" and rural OV LV BPL topologies allow the safe hook detection as indicated by their high $\triangle \mathrm{PES}$ values across the entire contour plot.

- The hook distance from the transmitting end influences the performance of HS-DET method only in the cases of OV LV BPL topologies with high number of branches. In these cases, the hook insertion that is treated as a branch from the hybrid model influences the multipath propagation of the original OV LV BPL topology. Depending on the hook length, the presence of the hook may change the channel transfer function and, thus, $\triangle$ PES of the modified OV LV BPL topology -see Figs. 3(a)-(c)-. In contrast, modified rural and "LOS" OV LV BPL topologies present little dependence on the hook distance from the transmitting end since the BPL signal distances of the multipath propagation due to the hook insertion remains almost the same for given modified rural and "LOS" OV LV BPL topologies -see Figs. 3(d) and (e)-.

- Regardless of the examined OV LV BPL topology, the performance of HS-DET method mainly depends on the hook length. The detection of the hook style energy theft becomes easier when the hook remains short enough (i.e., shorter than $10 \mathrm{~m}$ ). In all the cases examined, when the hook exceeds $10 \mathrm{~m}$, the performance of HS-DET decreases. This is evident since longer branches create rare and shallow notches in channel transfer functions that little affect $\triangle$ PES. Anyway, in all the cases examined, $\triangle \mathrm{PES}$ receives significant high values that permit the easy detection. 
- In general, when modified OV LV BPL topologies with branches and long hooks are investigated, HS-DET method more easily detects the energy theft of hooks that are situated at the middle of the transmission path rather than near the transmitting and receiving ends. This is clear in contour plots of Figs. 3(a)-(d) through the presence of islands of darker colors near to the transmitting and receiving ends. As the number of branches increases and their length gets shorter, the presence of island of darker colors becomes more intense -see Fig. 3(b)-.

\subsection{HS-DET with Measurement Differences}

The performance of HS-DET has been investigated in Sec. 4.1 when measurement differences are ignored. Its performance primarily depends on the hook length as well as the examined OV LV BPL topology. The detection of hook style theft becomes easiest when short length hooks are deployed in "LOS" OV LV BPL topologies. It is evident that the existence of measurement differences will deteriorate the performance of HS-DET method. In this subsection, it is examined the degree of performance deterioration of HS-DET method in terms of $\triangle \mathrm{PES}$ when various CUDs are assumed.

With reference to Fig. 2(b) and Table 2, let assume that the same hook of length $L_{\mathrm{bh}}$ is inserted at distance $D_{\mathrm{h}}$ from the transmitting end. In Table $3, \overline{P E S_{\text {or }}}, \overline{P E S_{\text {mod }}}$ and $\overline{\triangle P E S}$ are reported when $L_{\mathrm{bh}}=5 \mathrm{~m}$ and $D_{\mathrm{h}}=300 \mathrm{~m}$ are assumed for the five indicative OV LV BPL topologies and different maximum value $a_{\text {CUD }}$ of CUD are assumed.

Table 3. PES Metrics of Indicative OV LV BPL Topologies when $L_{\mathrm{bh}}=5 \mathrm{~m}$ and $D_{\mathrm{h}}=300 \mathrm{~m}$ for different maximum values $a_{\mathrm{CUD}}$

\begin{tabular}{|c|c|c|c|c|c|c|c|c|c|c|c|c|c|c|c|}
\hline & \multicolumn{3}{|c|}{$a_{\mathrm{CUD}}=1 \mathrm{~dB}$} & \multicolumn{3}{|c|}{$a_{\text {CUD }}=2 \mathrm{~dB}$} & \multicolumn{3}{|c|}{$a_{\text {CUD }}=3 \mathrm{~dB}$} & \multicolumn{3}{|c|}{$a_{\text {CUD }}=4 \mathrm{~dB}$} & \multicolumn{3}{|c|}{$a_{\text {cUD }}=5 \mathrm{~dB}$} \\
\hline $\begin{array}{c}\text { OV LV } \\
\text { BPL } \\
\text { Topology }\end{array}$ & $\begin{array}{c}\overline{P E S_{\text {or }}} \\
(\%)\end{array}$ & $\begin{array}{c}P E S_{\text {mod }} \\
(\%)\end{array}$ & $\begin{array}{l}\overline{\overline{\triangle P E S}} \\
(\%)\end{array}$ & $\begin{array}{c}\overline{P E S_{\text {or }}} \\
(\%)\end{array}$ & $\begin{array}{c}P E S_{\text {mod }} \\
(\%)\end{array}$ & $\begin{array}{l}\overline{\overline{\triangle P E S}} \\
(\%)\end{array}$ & $\begin{array}{c}\overline{\bar{P}} \\
\left(\% S_{\text {or }}\right.\end{array}$ & $\begin{array}{c}P E S_{\text {mod }} \\
(\%)\end{array}$ & $\begin{array}{l}\overline{\overline{\Delta P E S}} \\
(\%)\end{array}$ & $\begin{array}{c}\overline{P E S_{\text {or }}} \\
(\%)\end{array}$ & $\begin{array}{c}P E S_{\text {mod }} \\
(\%)\end{array}$ & $\begin{array}{l}\overline{\overline{\triangle P E S}} \\
(\%)\end{array}$ & $\begin{array}{c}\overline{P E S_{\text {or }}} \\
(\%)\end{array}$ & $\begin{array}{c}\overline{P E S_{\text {mod }}} \\
(\%)\end{array}$ & $\begin{array}{c}\overline{\overline{\triangle P E S}} \\
(\%)\end{array}$ \\
\hline $\begin{array}{l}\text { Urban } \\
\text { case A }\end{array}$ & 3.94 & 34.70 & 30.76 & 7.84 & 36.00 & 28.16 & 11.39 & 37.39 & 26.00 & 15.14 & 39.65 & 24.50 & 18.95 & 42.11 & 23.15 \\
\hline $\begin{array}{l}\text { Urban } \\
\text { case B }\end{array}$ & 2.60 & 28.75 & 26.15 & 5.19 & 29.09 & 23.90 & 7.61 & 30.18 & 22.56 & 10.18 & 31.49 & 21.31 & 12.73 & 32.42 & 19.69 \\
\hline $\begin{array}{c}\text { Suburban } \\
\text { case }\end{array}$ & 5.83 & 50.53 & 44.70 & 11.58 & 52.55 & 40.97 & 16.70 & 54.53 & 37.83 & 21.98 & 57.58 & 35.61 & 26.97 & 60.87 & 33.90 \\
\hline Rural case & 9.54 & 76.36 & 66.82 & 18.96 & 79.36 & 60.40 & 26.88 & 84.78 & 57.90 & 34.89 & 89.60 & 54.71 & 42.52 & 95.23 & 52.71 \\
\hline $\begin{array}{l}\text { "LOS" } \\
\text { case }\end{array}$ & 33.57 & 257.46 & 223.89 & 63.36 & 269.79 & 206.44 & 83.95 & 282.23 & 198.28 & 106.31 & 302.28 & 195.97 & 125.20 & 316.22 & 191.02 \\
\hline
\end{tabular}


From Table 3, $\overline{P E S_{\text {or }}}$ takes values greater than zero when measurement differences are considered. Actually, as the maximum value $a_{\mathrm{CUD}}$ increases, so does $\overline{P E S_{\text {or }}}$ for given original OV LV BPL topology. With reference to eq. (5), the increase of $\overline{P E S_{\text {or }}}$ unveils the anomaly that is added during the computation of coupling transfer functions of the original indicative OV LV BPL topologies due to the existence of measurement differences. At the same time, as the maximum value $a_{\mathrm{CUD}}$ increases, so does $\overline{P E S_{\text {mod }}}$ for given modified OV LV BPL topology. With reference to eq. (7), $\overline{\triangle P E S}$ focuses on the elimination of the impact of the measurement differences through the computation of the difference of $\overline{P E S_{\text {or }}}$ and $\overline{P E S_{\text {mod }}}$. As it is shown in Table 3, despite the intention of $\overline{\triangle P E S}$ to mitigate measurement differences, as the maximum value $a_{\text {CUD }}$ increases, $\overline{\triangle P E S}$ decreases for given OV LV BPL topology. Although the values of $\overline{\triangle P E S}$ decreases remain positive and significantly above zero in all the cases examined, the negative correlation between $\overline{\triangle P E S}$ and maximum value $a_{\mathrm{CUD}}$ indicates the difficulty in distinguishing energy theft during the application of HS-DET method when measurement differences occur. Anyway, the general behavior of $\triangle P E S$, which has been observed in Table 2, concerning its dependence on the examined OV LV BPL topology is also presented during the computation of $\overline{\triangle P E S}$ for given maximum value $a_{\text {CUD. }}$.

As already been mentioned in Sec. 4.1, HS-DET method should detect any hook style energy theft regardless of the examined OV LV BPL topology and the hook characteristics. Apart from the intrinsic difficulties of HS-DET method presented in Figs. 3(a)-(e), the performance of HS-DET method is here assessed when measurement differences of various maximum values $a_{\text {CUD }}$ are considered. To investigate the sensitivity of HS-DET method performance against measurement differences, in Fig. 4(a), $\overline{\triangle P E S}$ is plotted versus the hook distance from the transmitting end and the hook length when the OV LV BPL topology of urban case A is assumed and CUD of maximum value $a_{\text {CUD }}$ equal to $1 \mathrm{~dB}$ is considered. In Figs. 4(b)-(e), same plots with Fig. 4(a) are given but for the case of the maximum value $a_{\mathrm{CUD}}$ being equal to $2 \mathrm{~dB}, 3 \mathrm{~dB}$, $4 \mathrm{~dB}$ and 5dB, respectively. In Figs. 5(a)-(e), Figs. 6(a)-(e), Figs. 7(a)-(e) and Figs. 8(a)-(e), same contour plots with Figs. 4(a)-(e) are given but for the case of urban case B, suburban case, rural case and "LOS" case, respectively. Here, it should be noticed that the same assumptions concerning the hook distance from the transmitting end span, the hook length span, the range of the hook distance from the transmitting end and the range of the hook length remain the same with Sec. 4.1. 


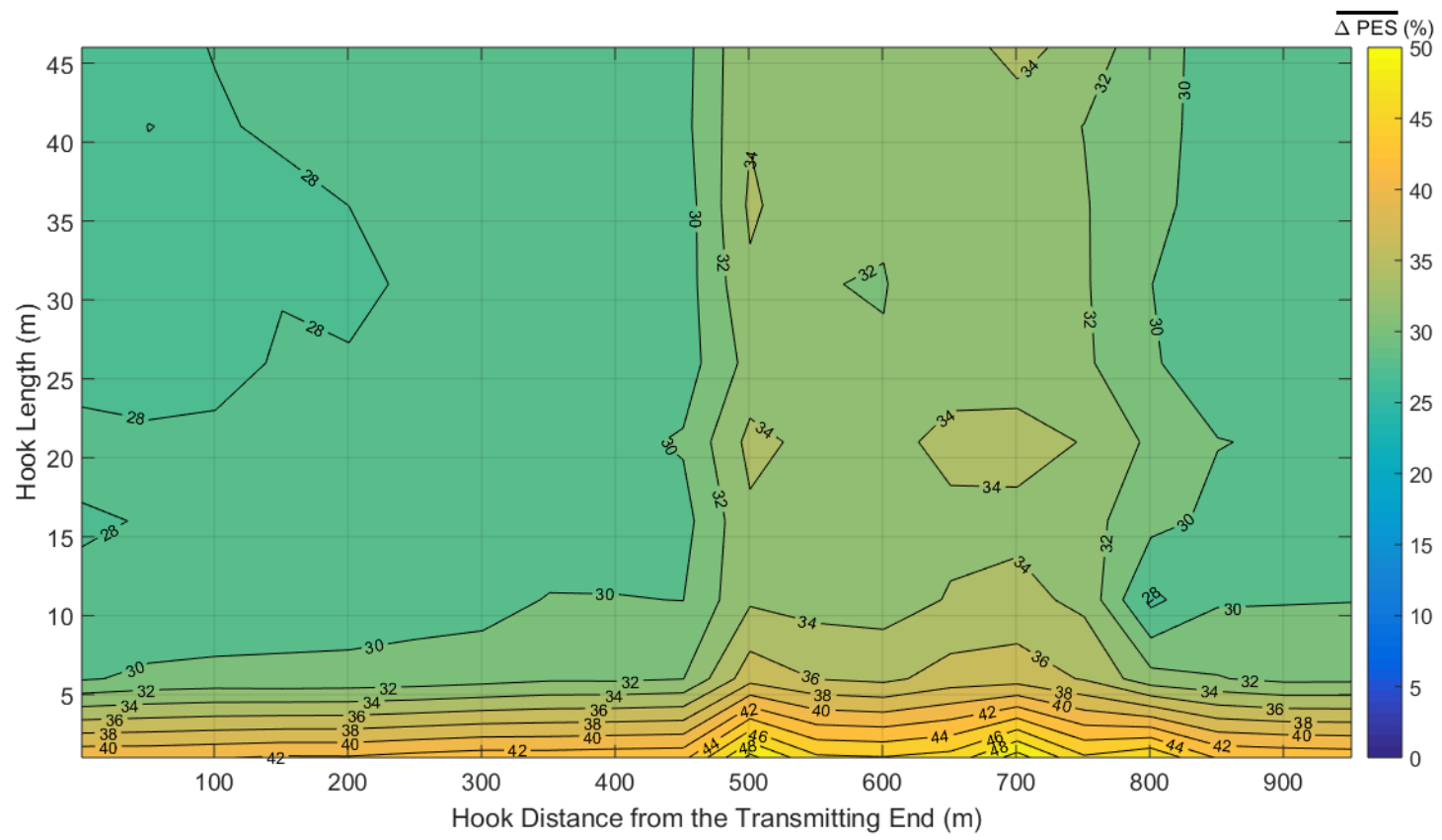

(a)

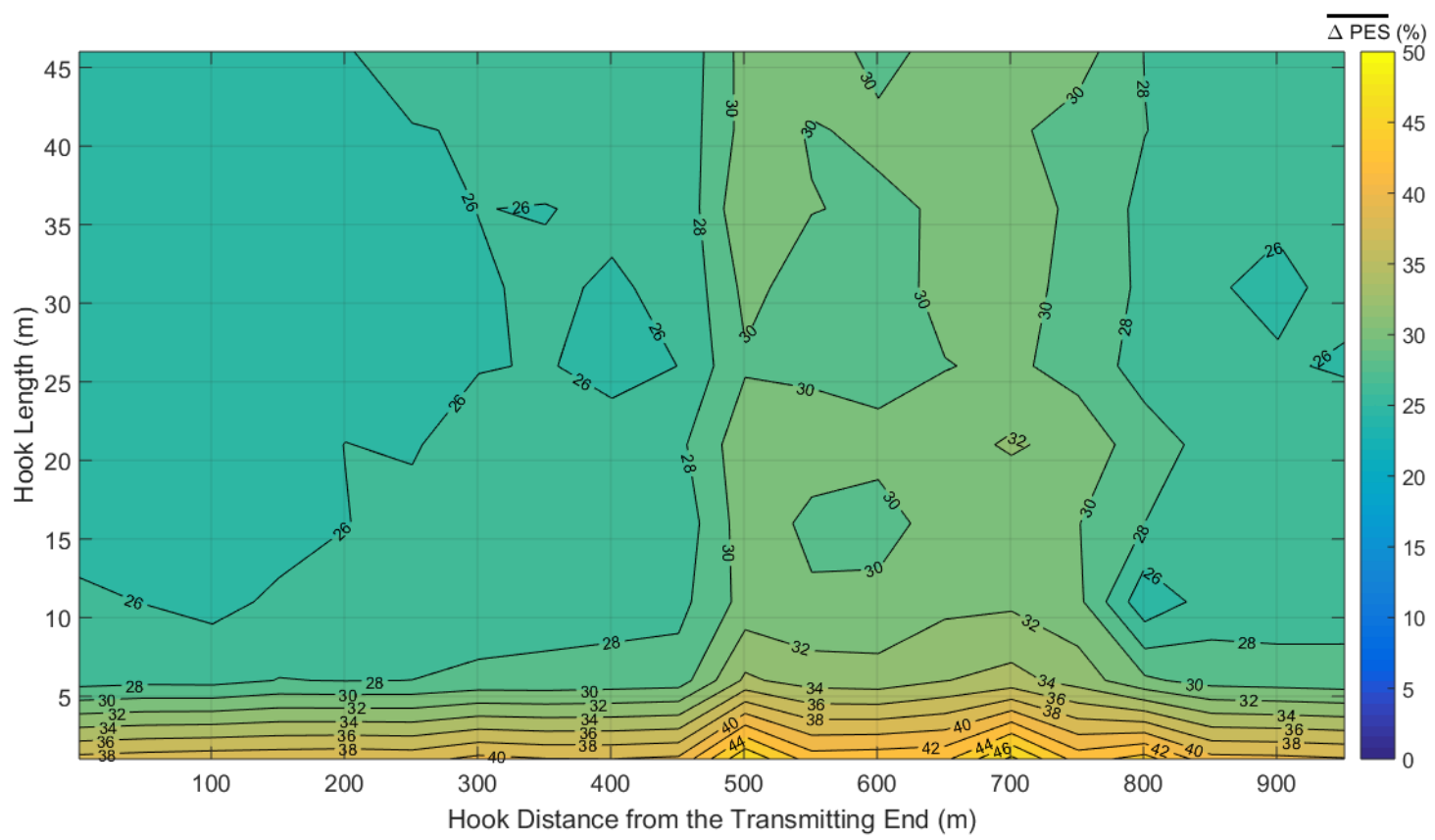

(b) 


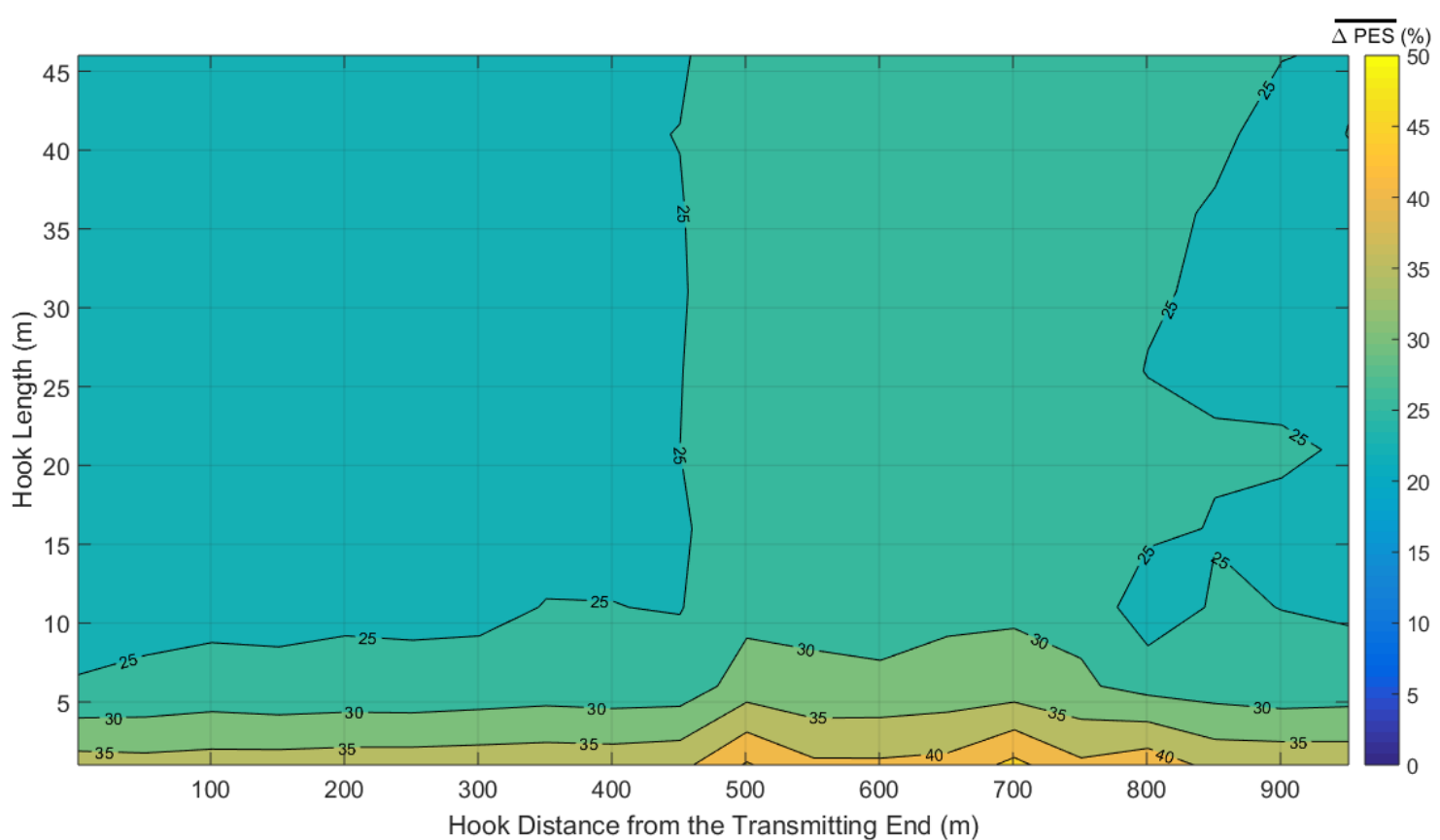

(c)

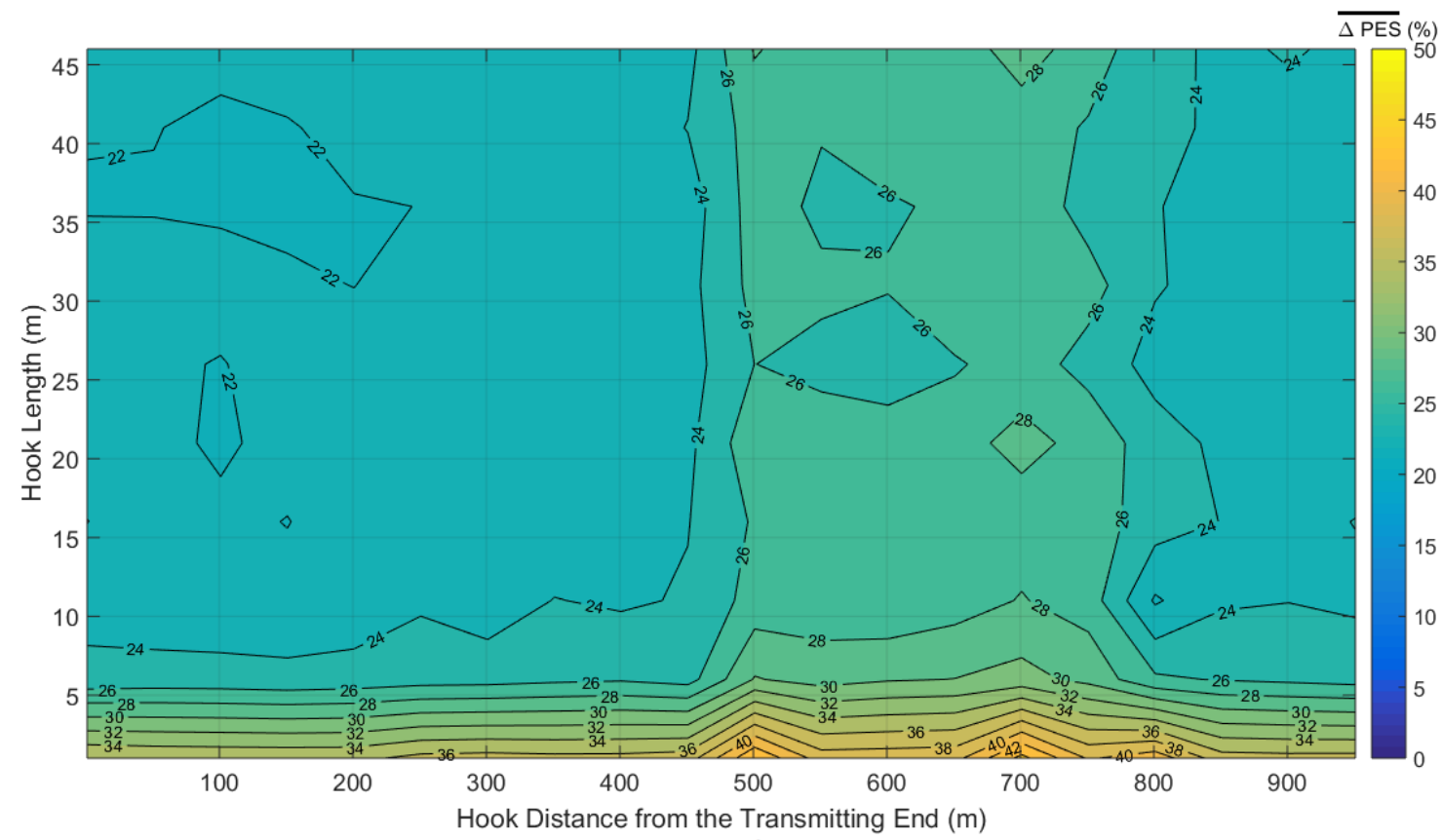

(d) 


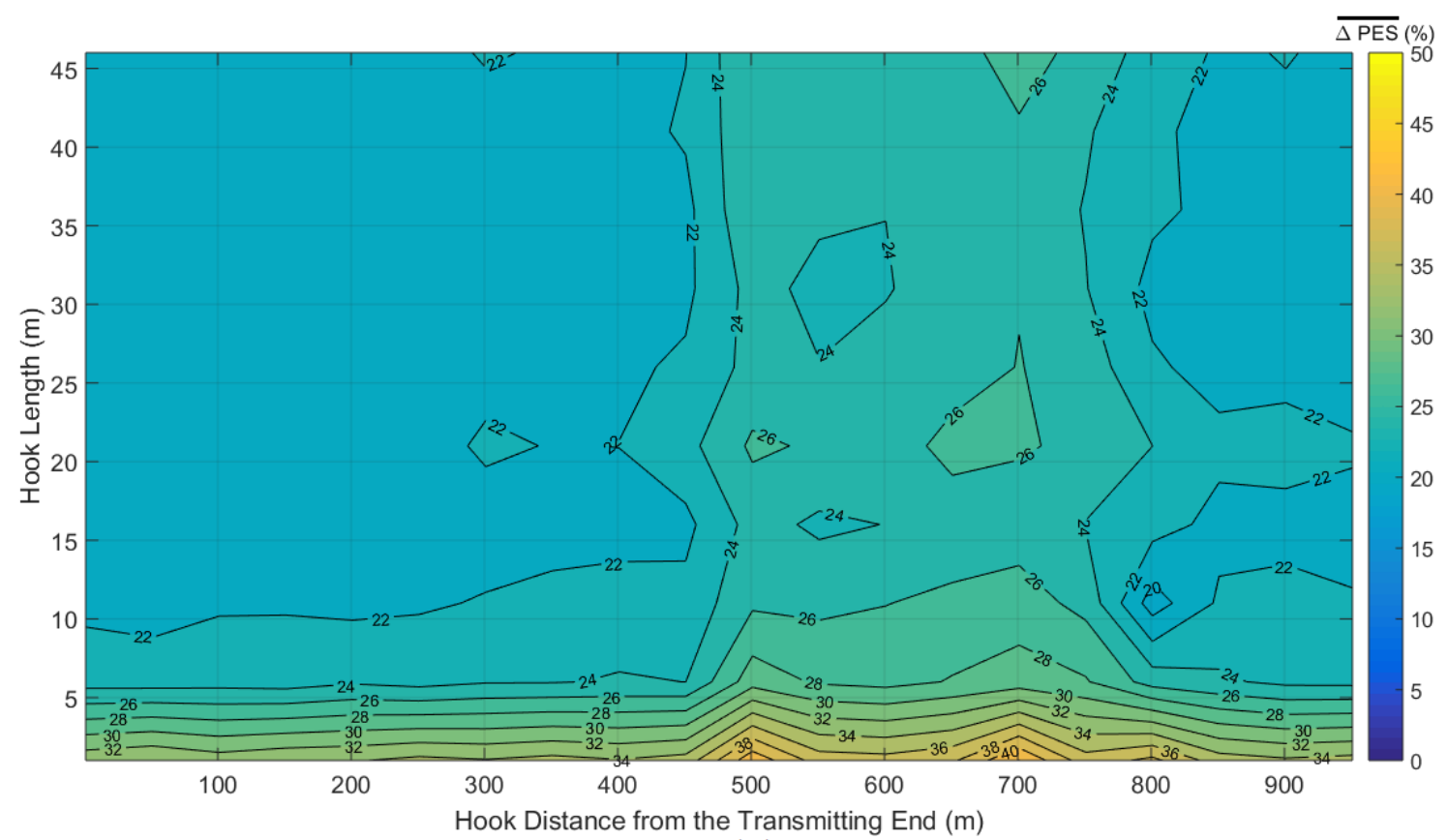

(e)

Fig. 4. $\overline{\triangle P E S}$ of the urban case $\mathrm{A}$ of the indicative OV LV BPL topologies in the $3-88 \mathrm{MHz}$ frequency band for various hook distances from the transmitting end and hook lengths when different maximum values $a_{\text {CUD }}$ are assumed. (a) $a_{\mathrm{CUD}}=1 \mathrm{~dB}$. (b) $a_{\mathrm{CUD}}=2 \mathrm{~dB}$. (c) $a_{\mathrm{CUD}}=3 \mathrm{~dB}$. (d) $a_{\mathrm{CUD}}=4 \mathrm{~dB}$. (e) $a_{\mathrm{CUD}}=5 \mathrm{~dB}$. 


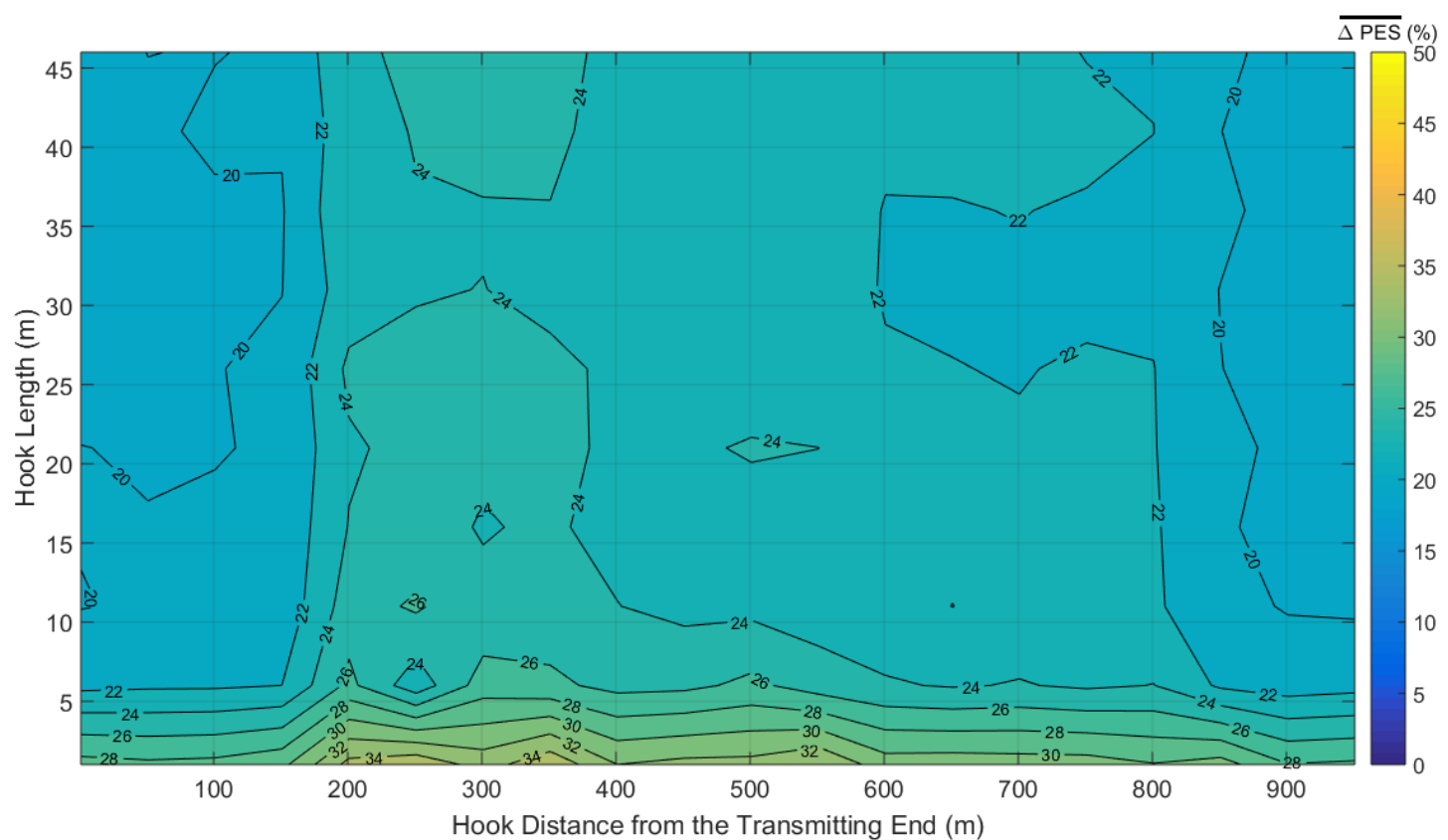

(a)

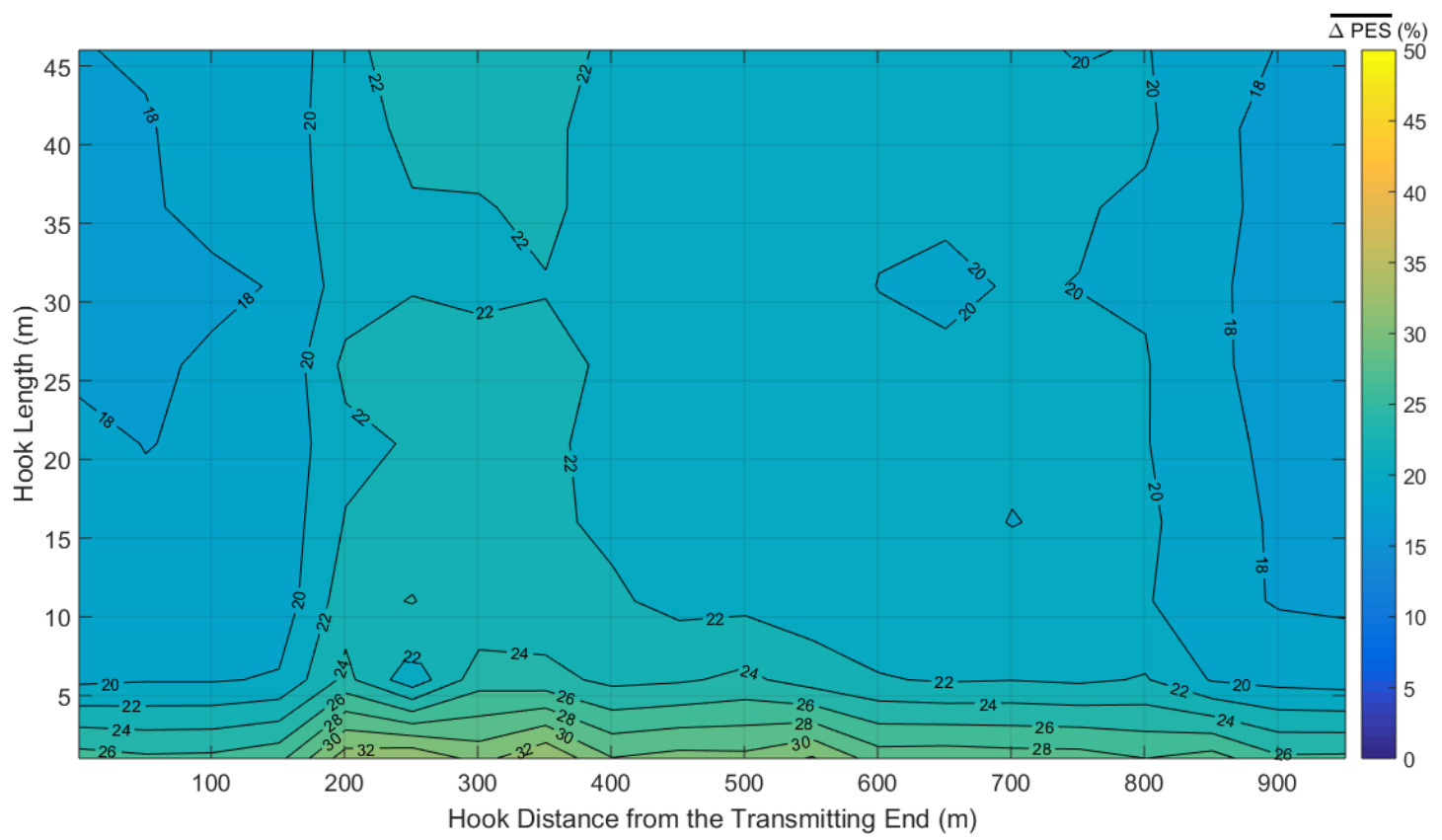

(b) 


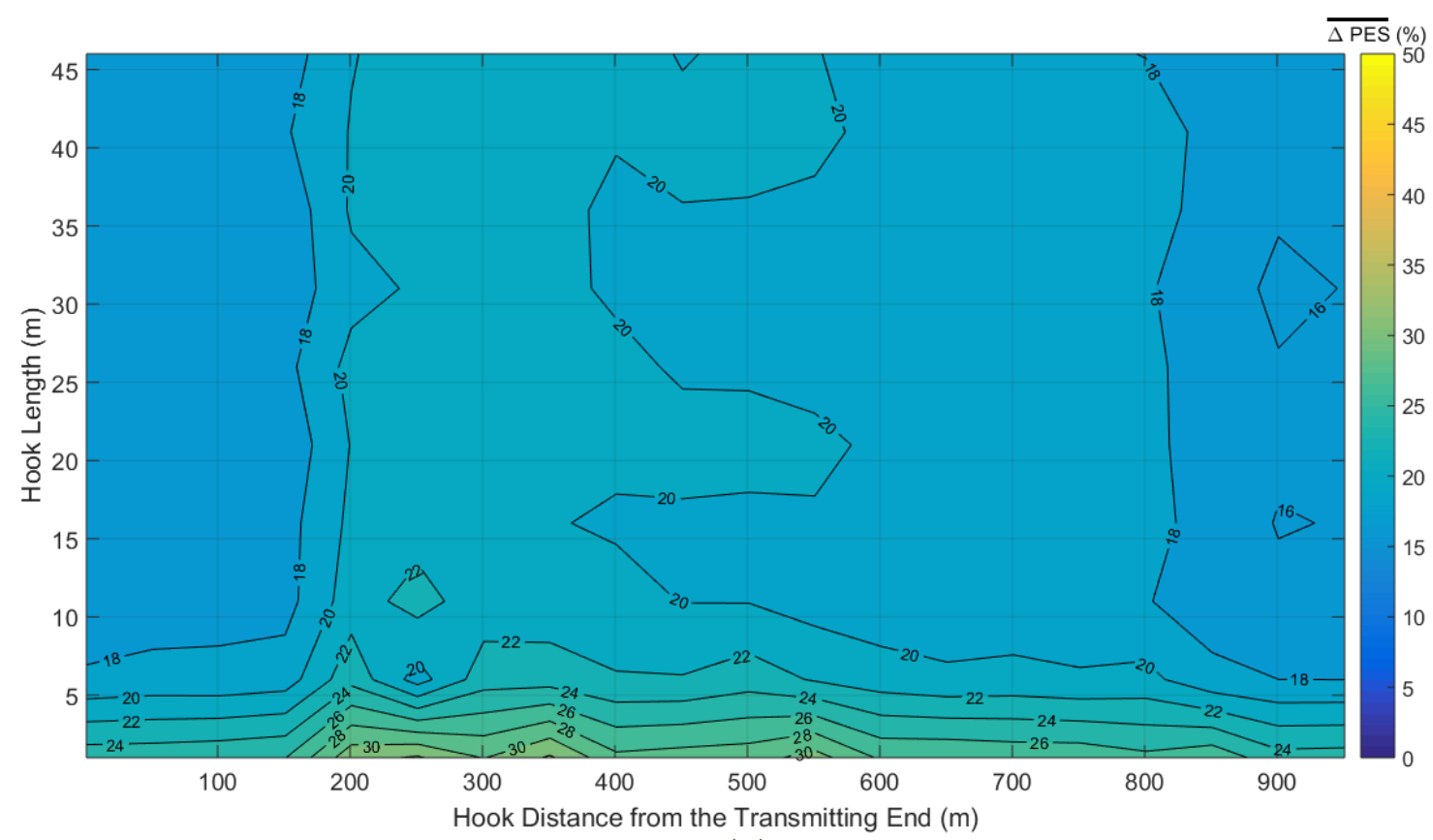

(c)

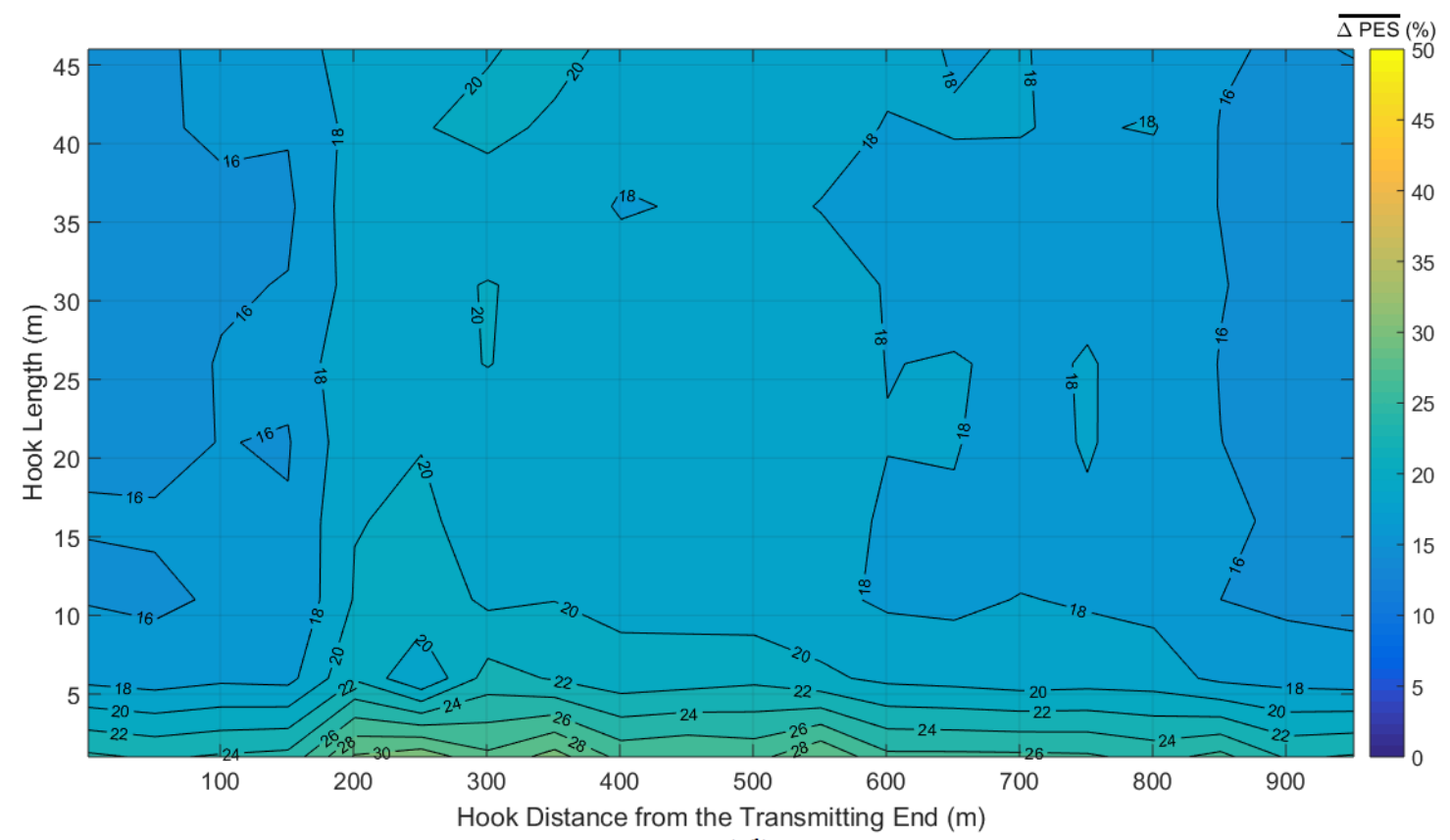

(d) 


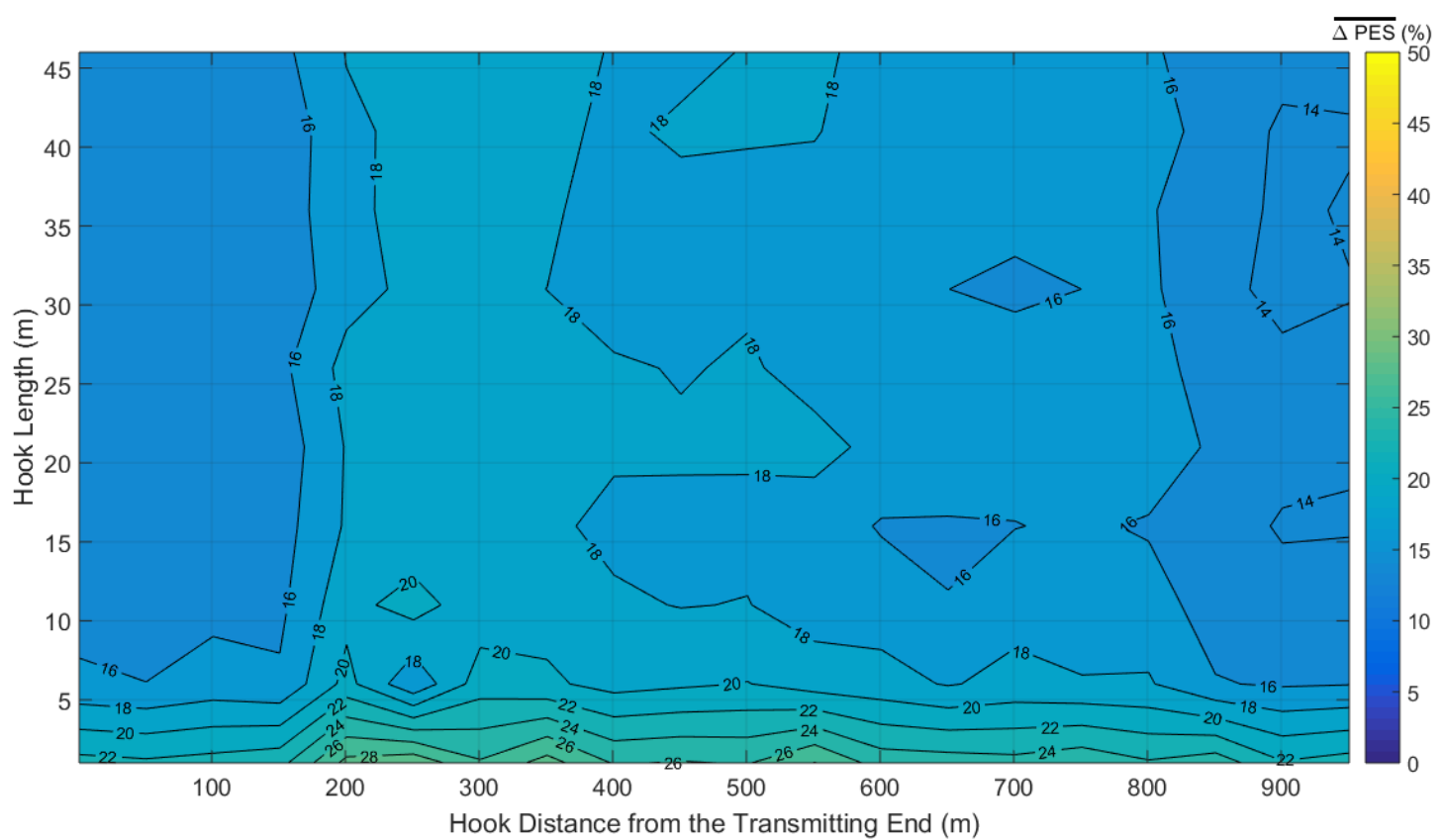

(e)

Fig. 5. Same curves with Fig. 4 but for the urban case B. 


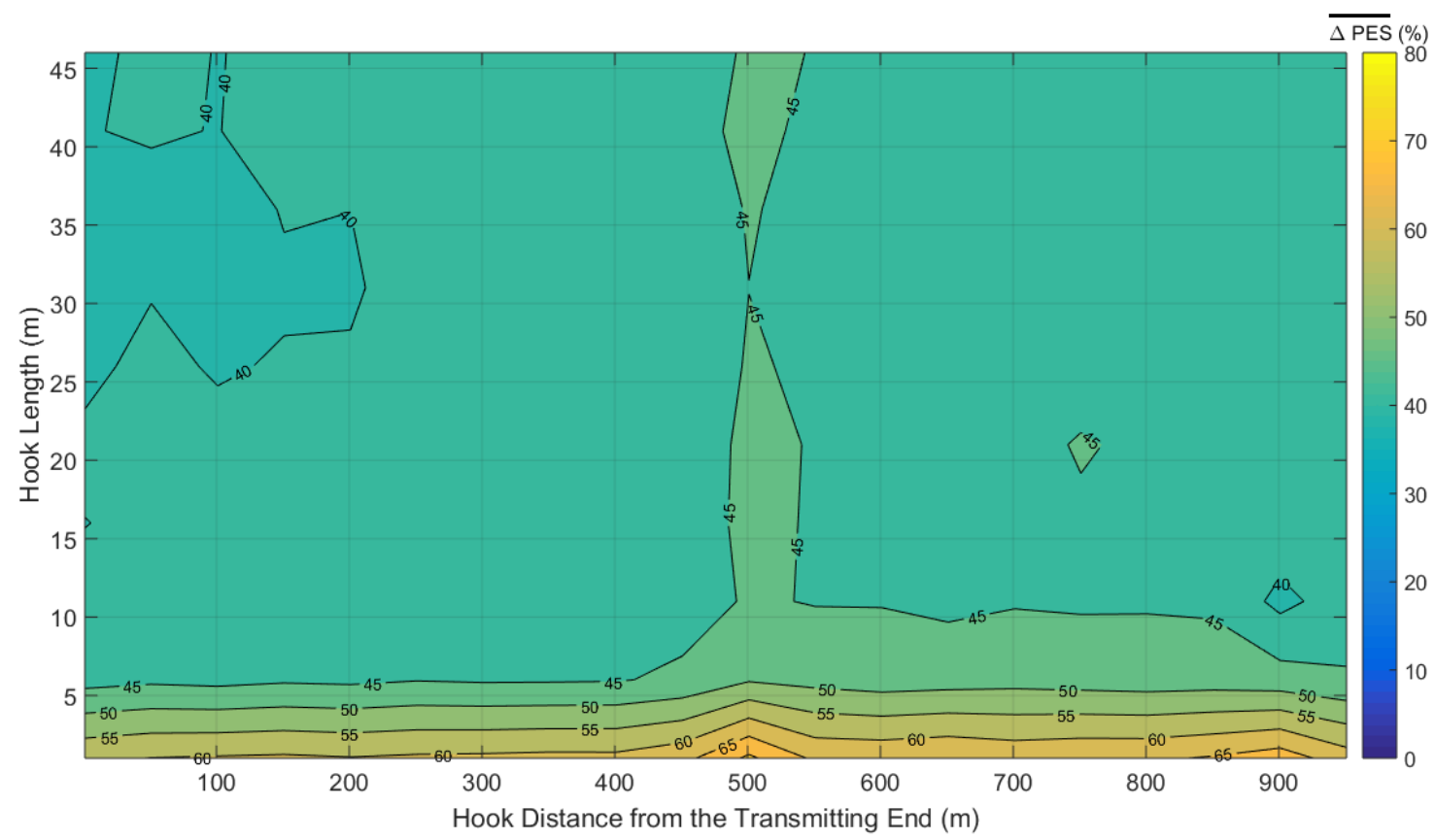

(a)

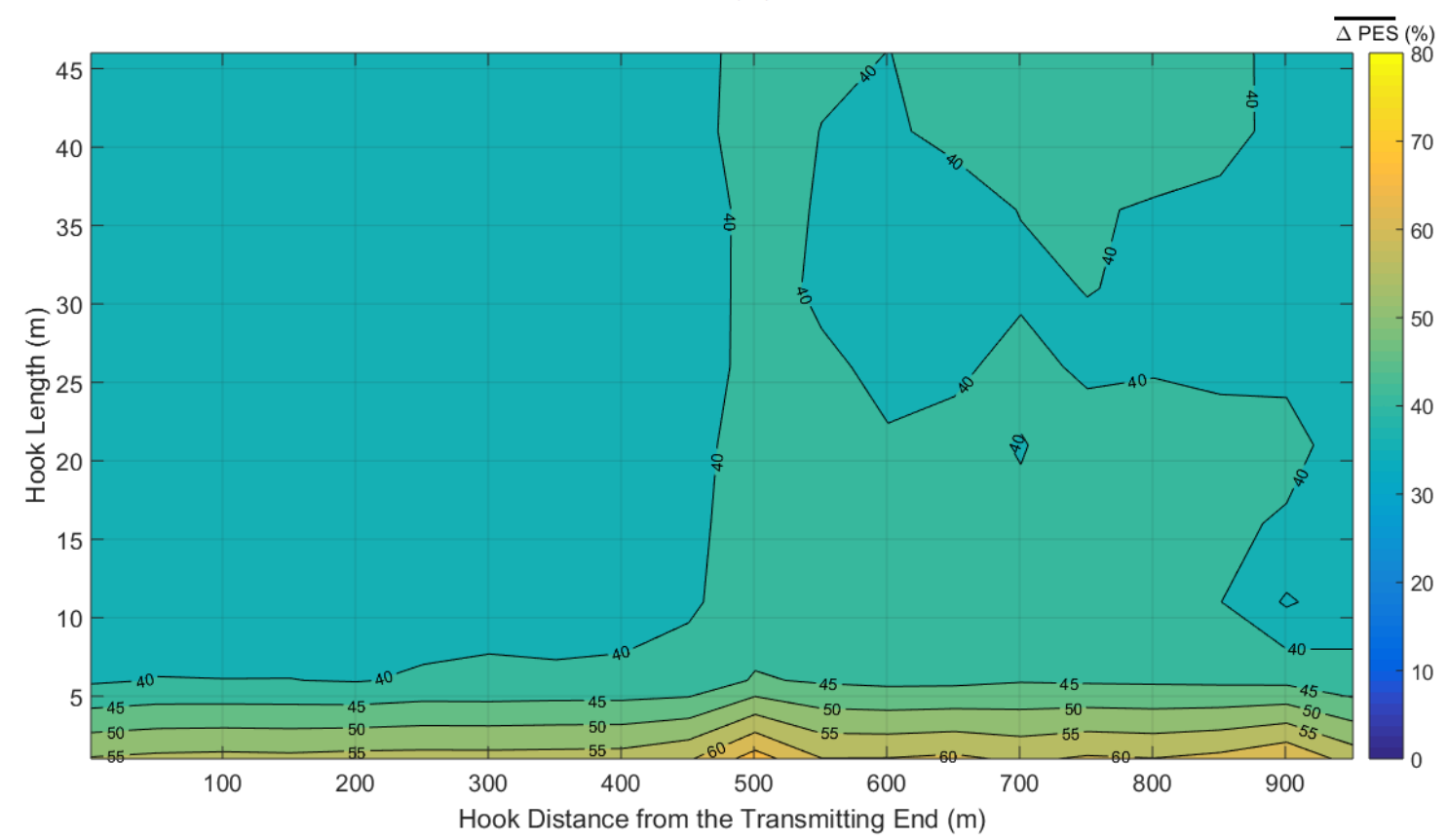

(b) 


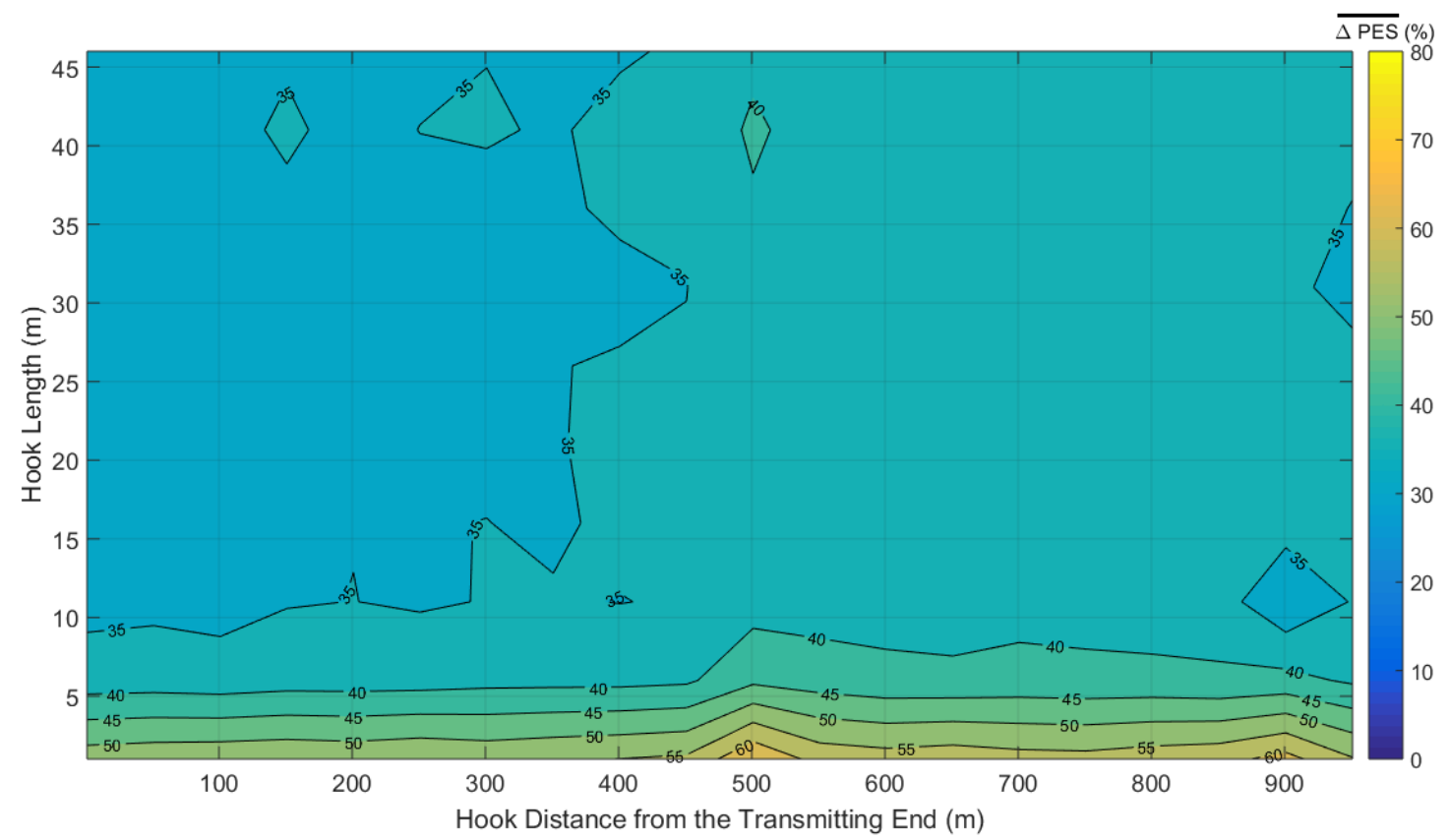

(c)

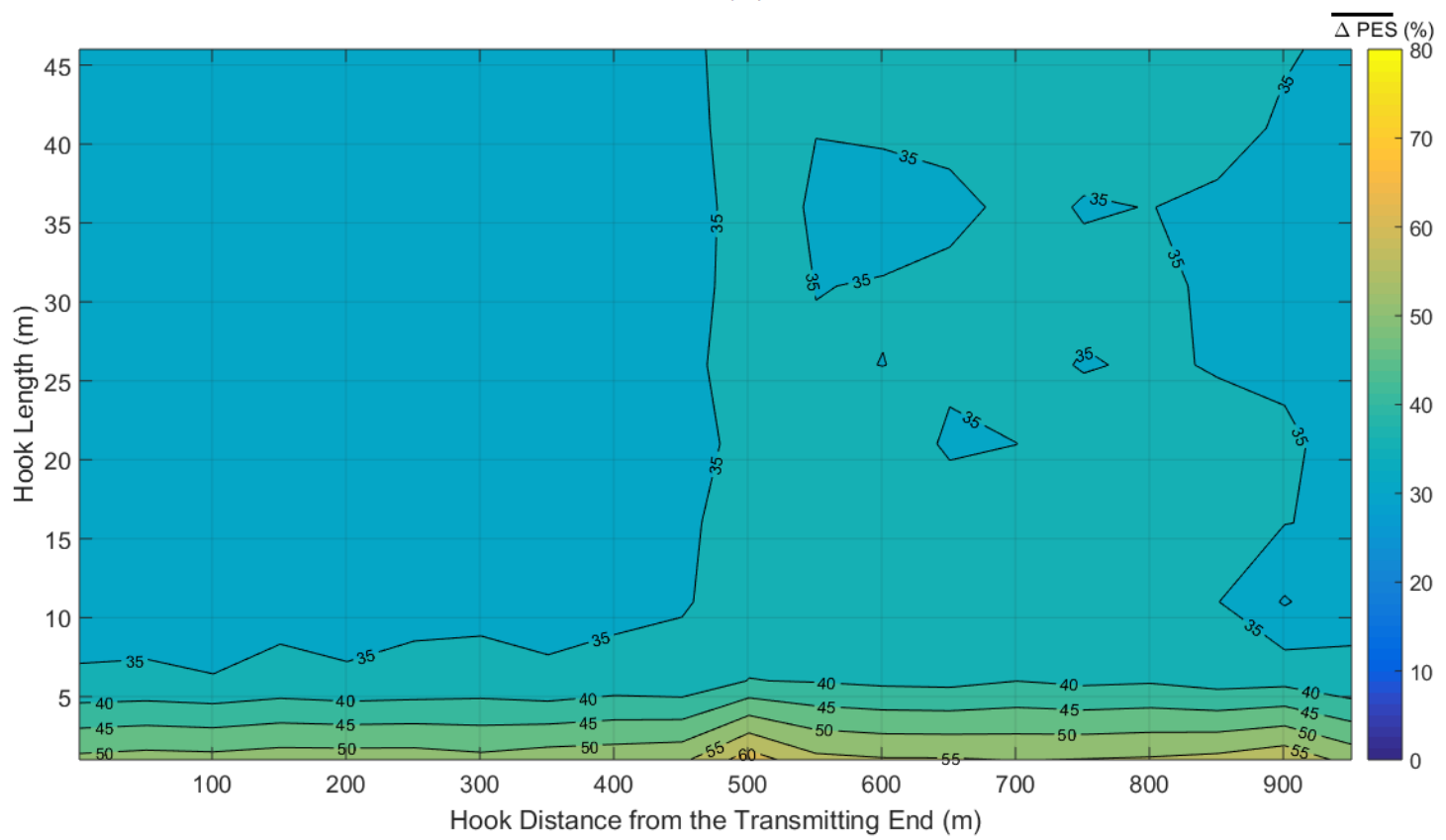

(d) 


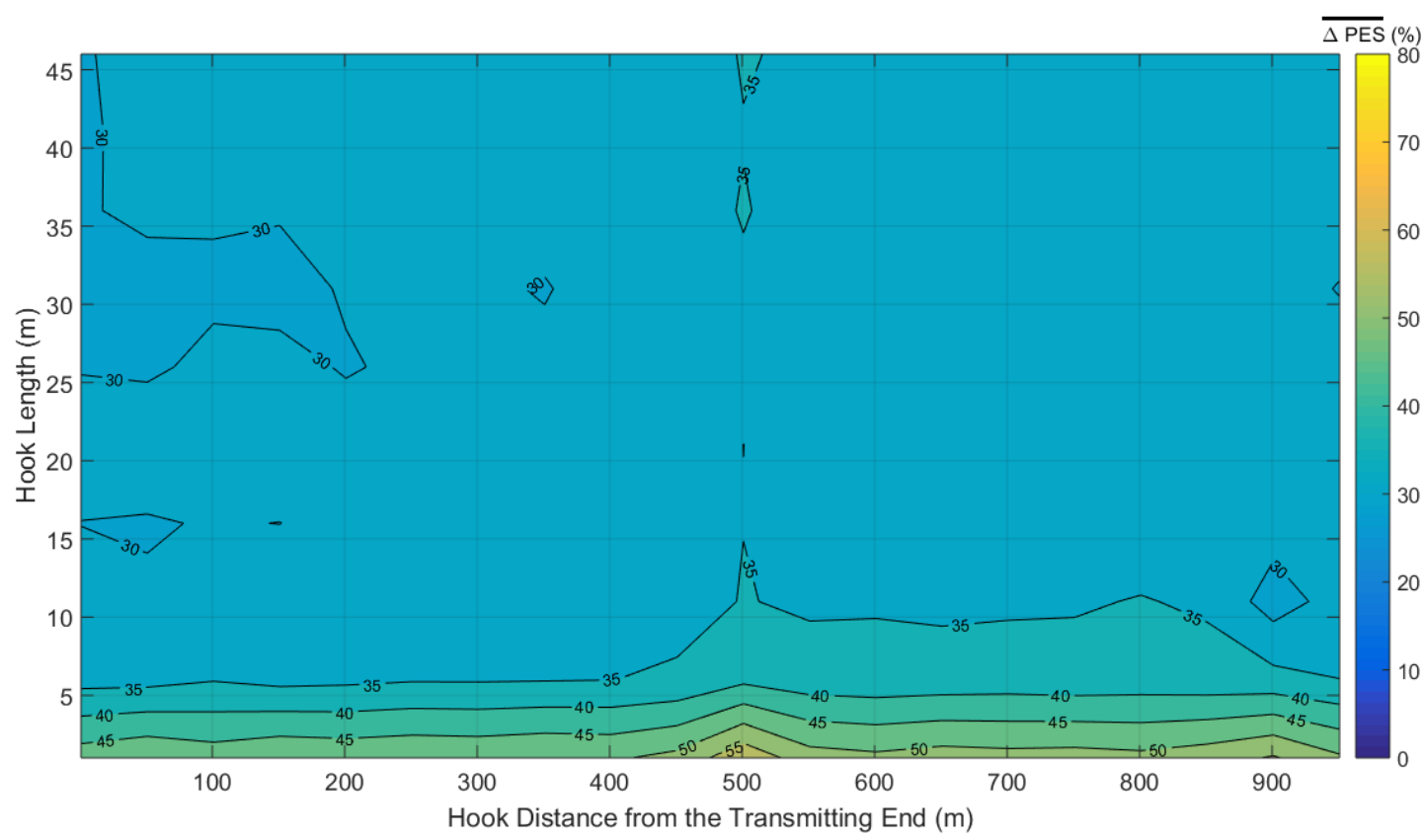

(e)

Fig. 6. Same curves with Fig. 4 but for the suburban case. 


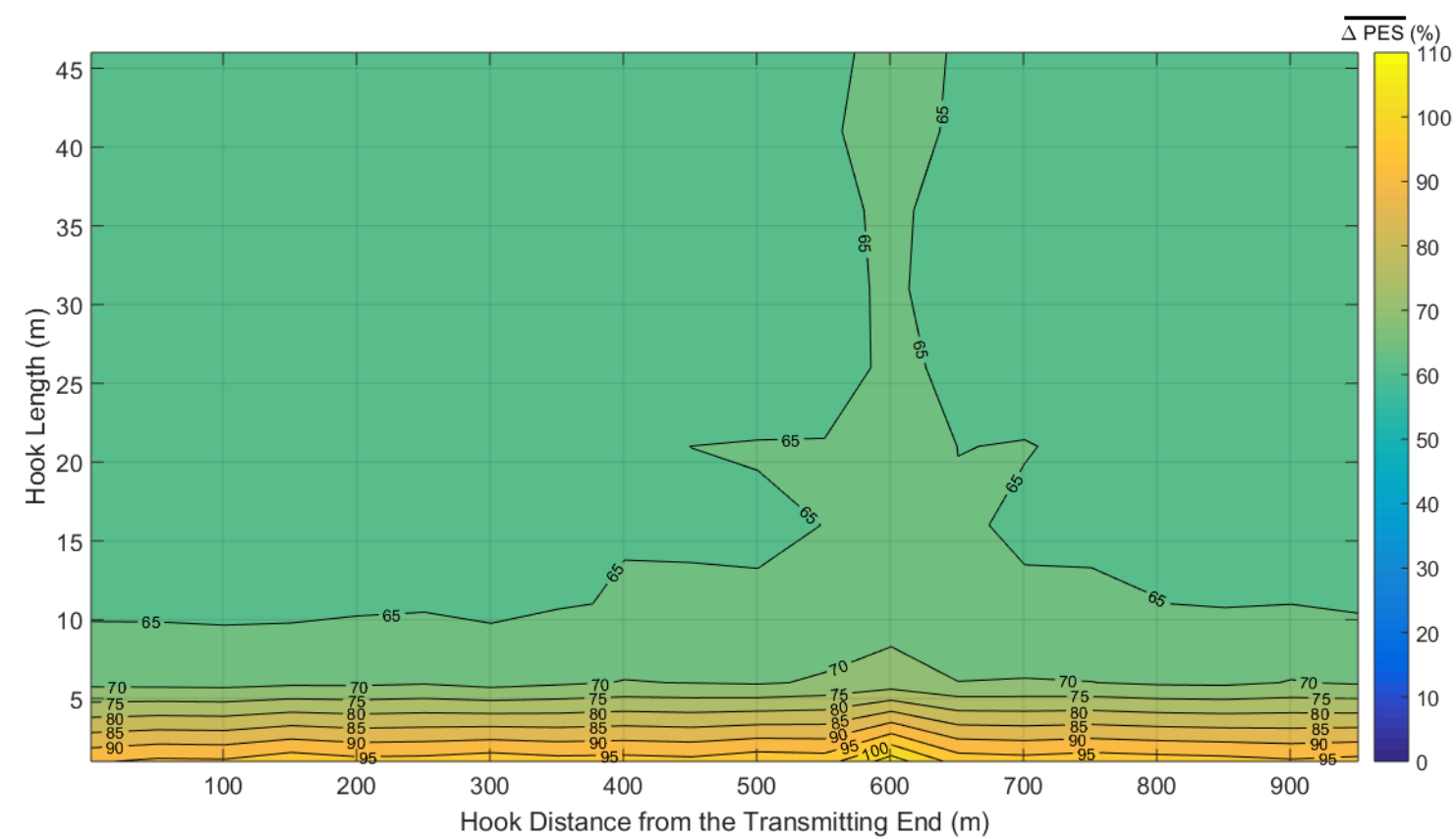

(a)

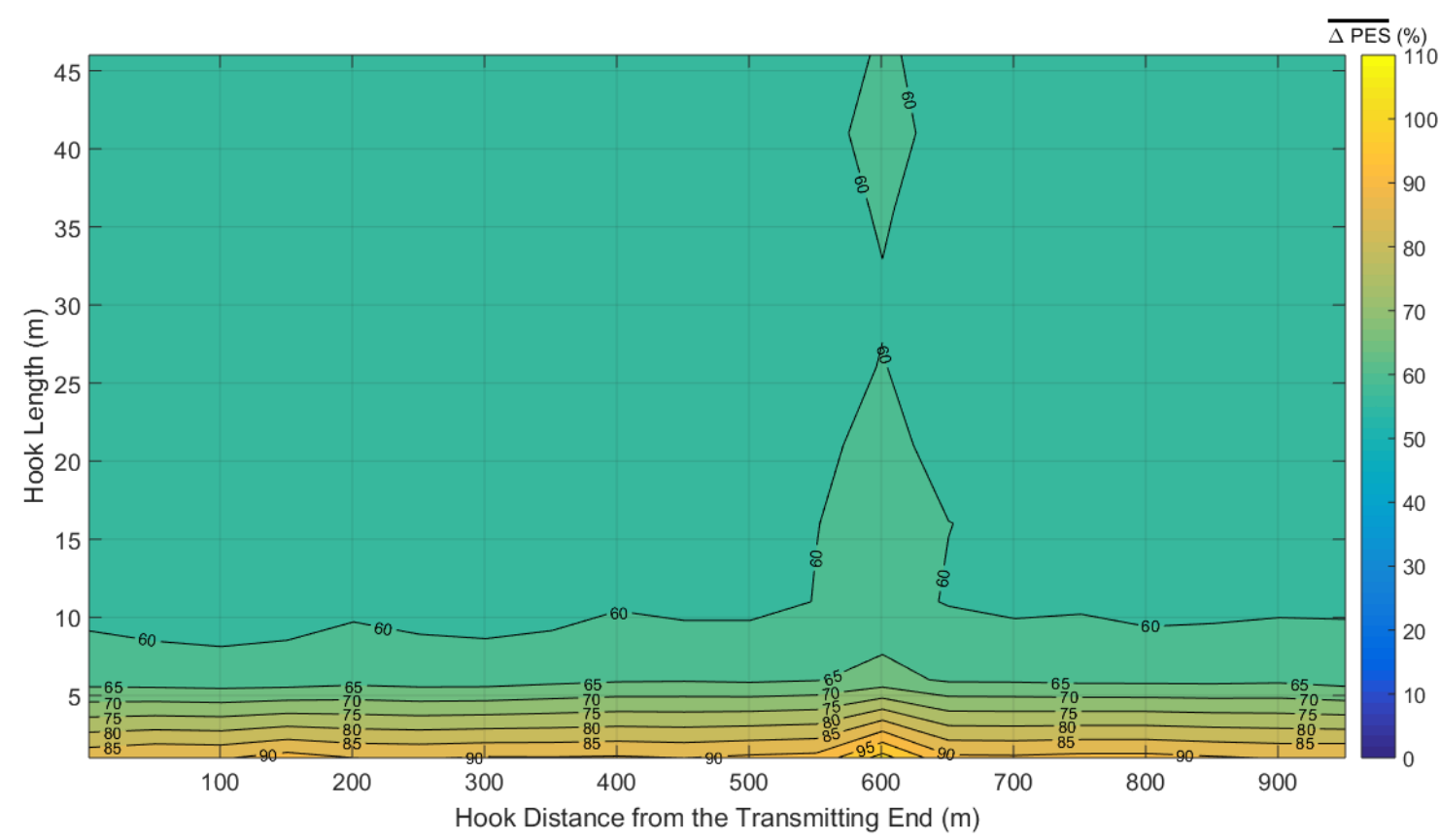

(b) 


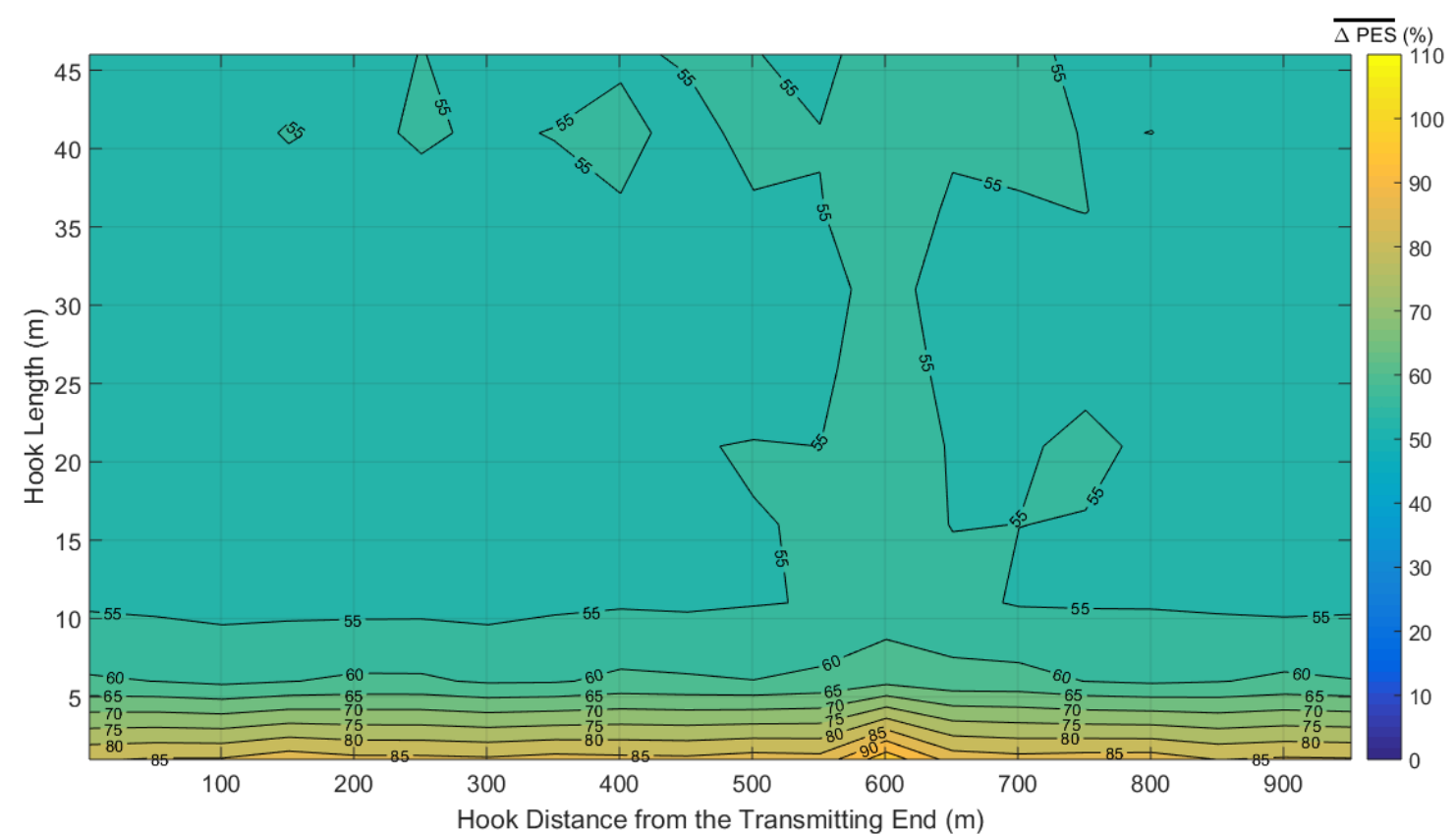

(c)

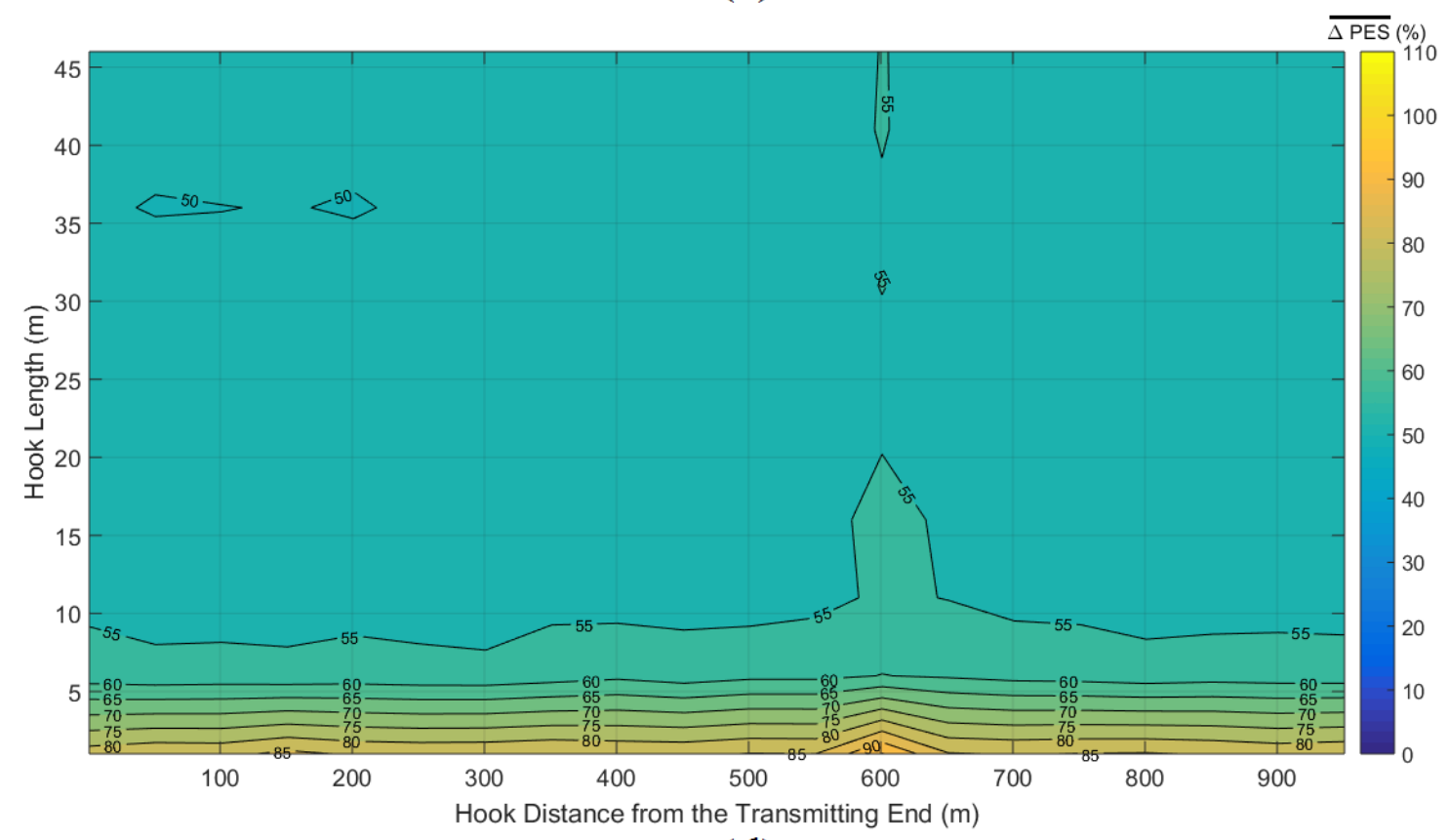

(d) 


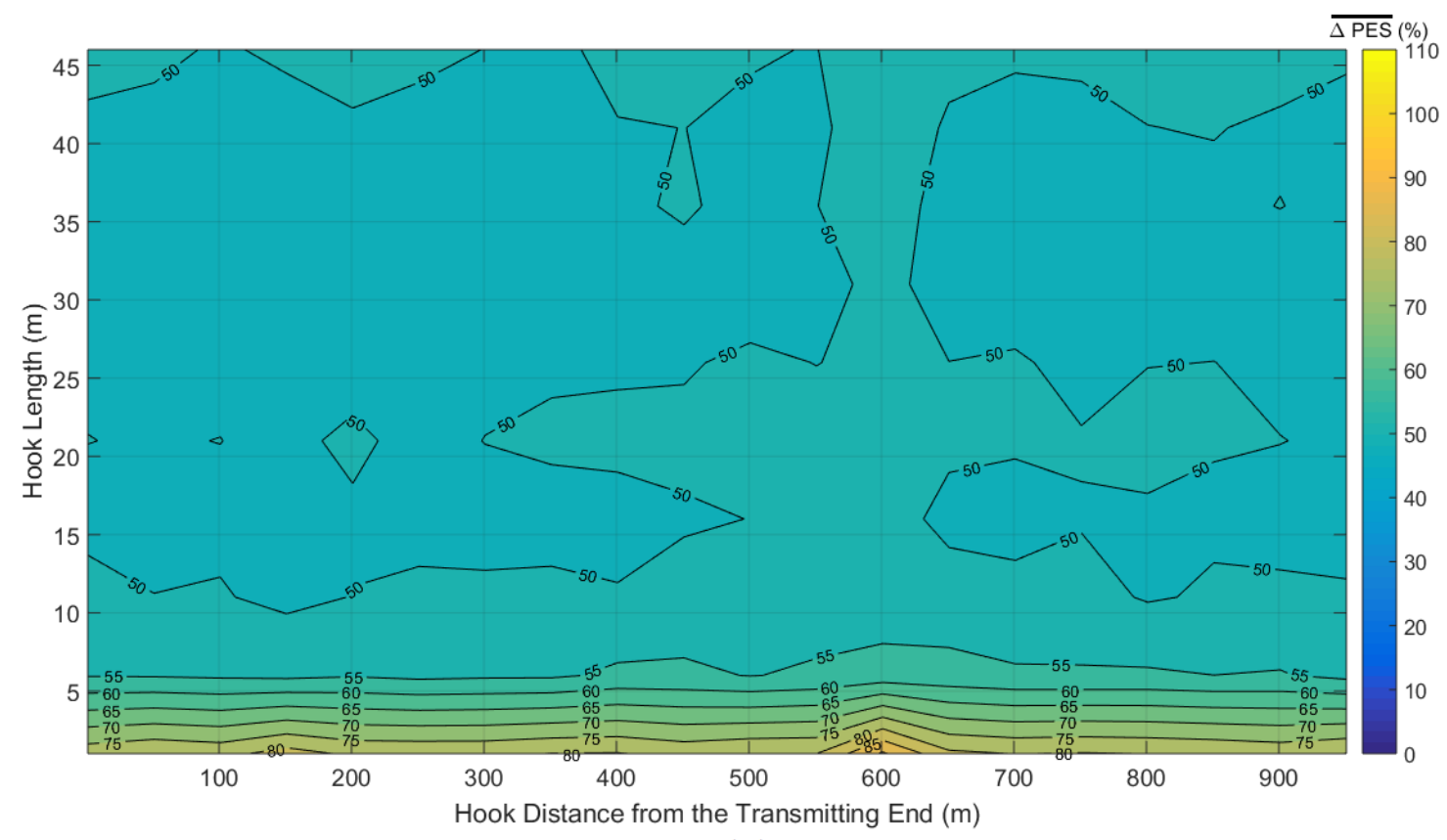

(e)

Fig. 7. Same curves with Fig. 4 but for the rural case. 


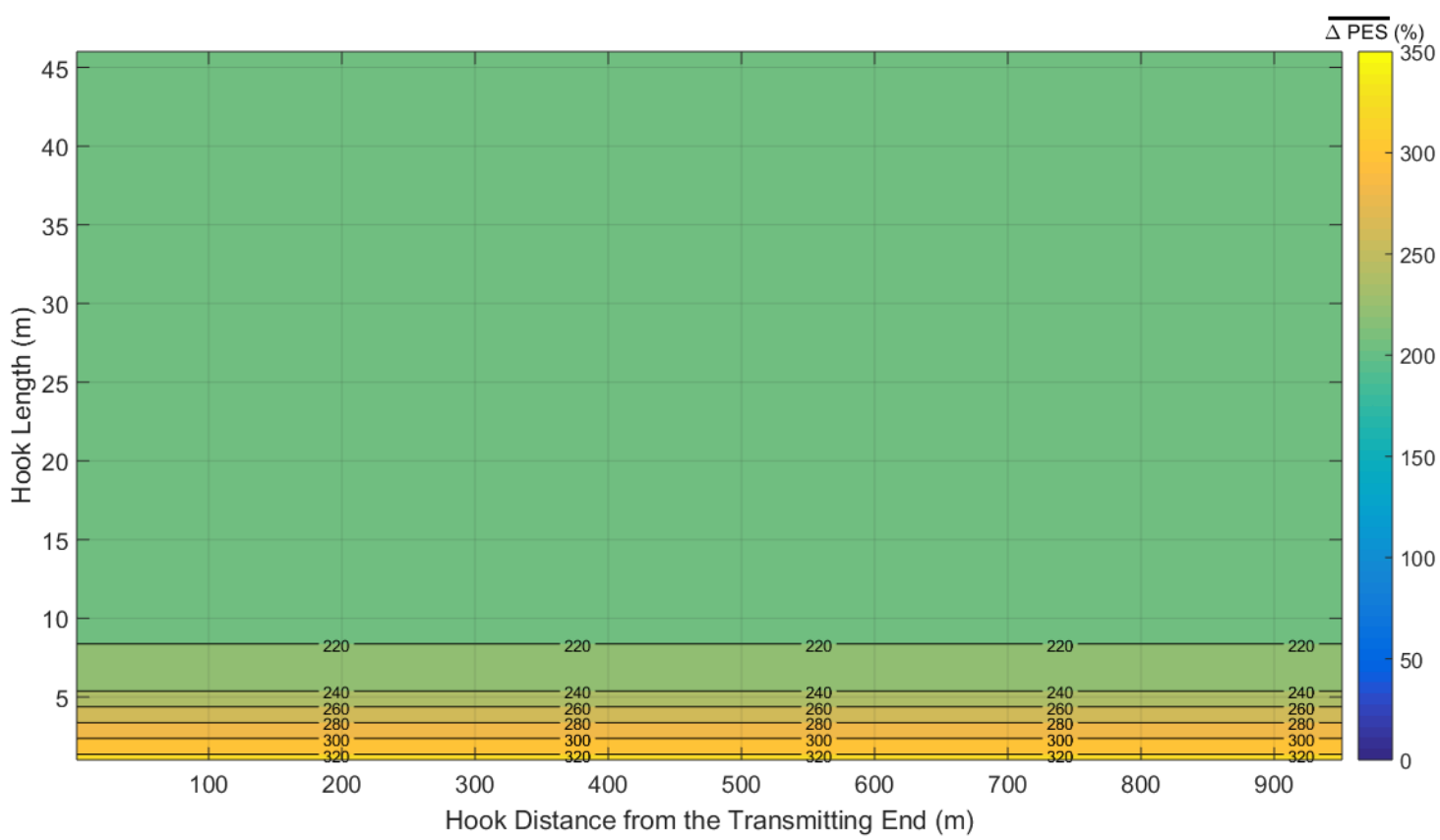

(a)

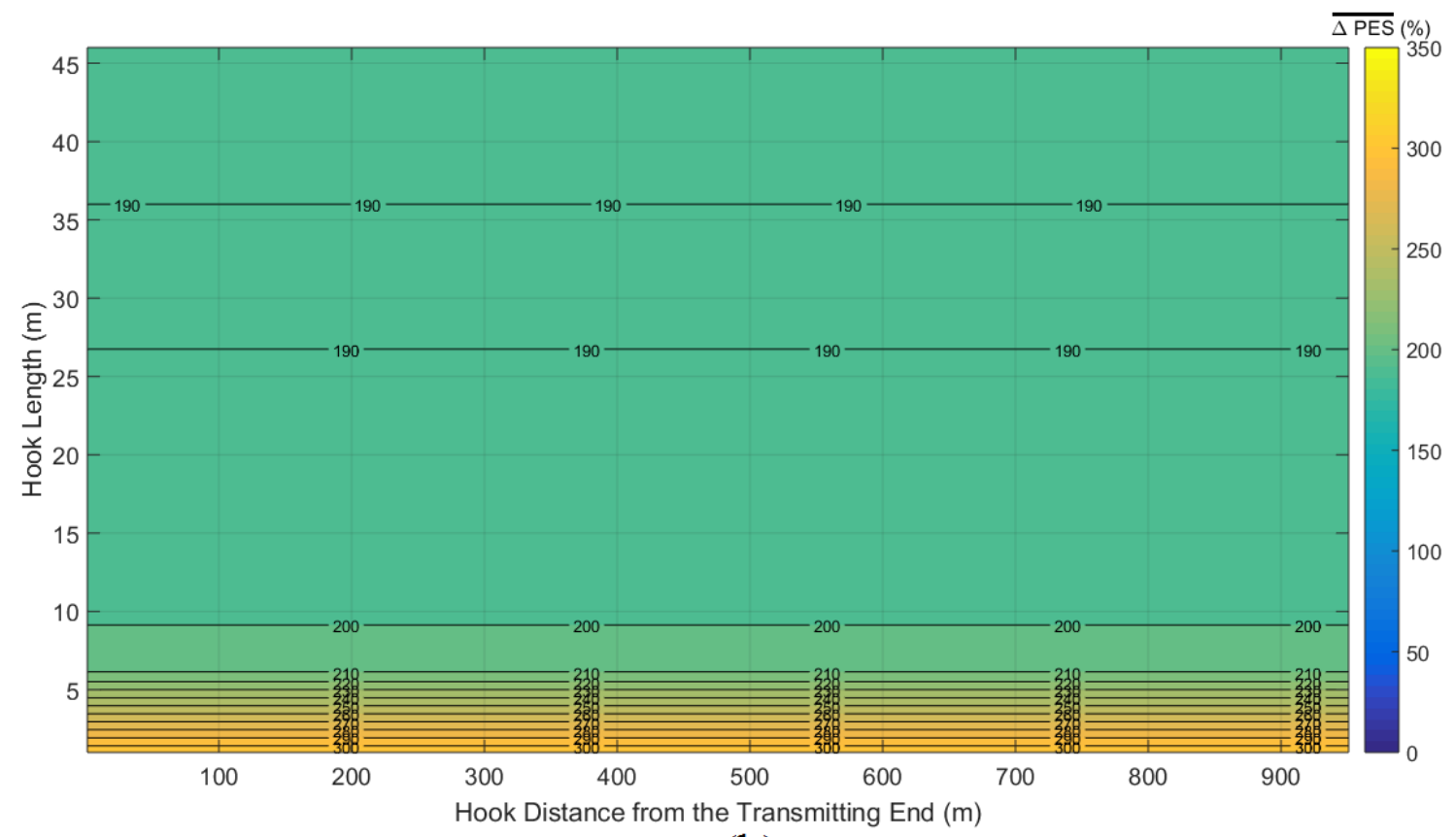

(b) 


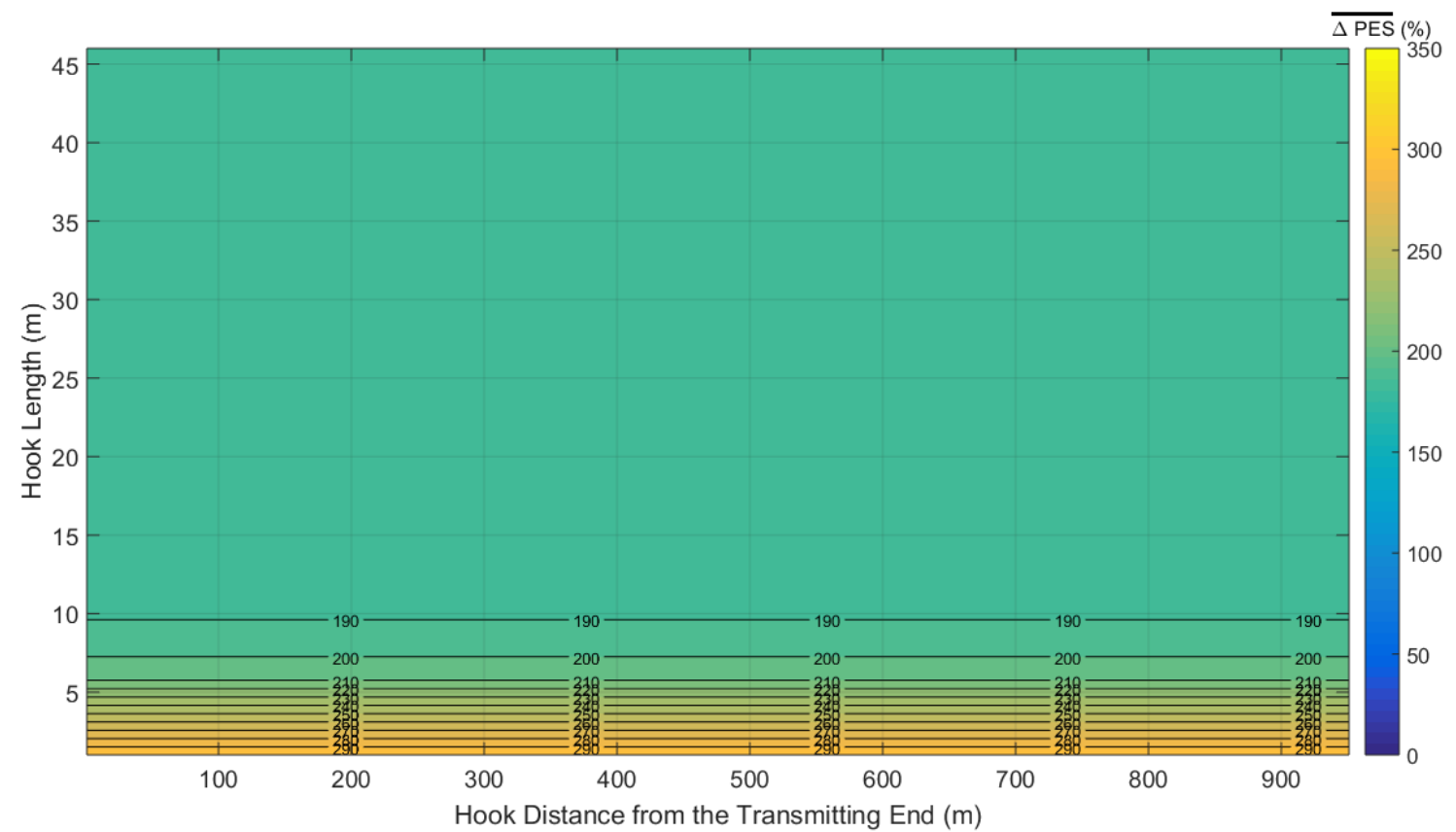

(c)

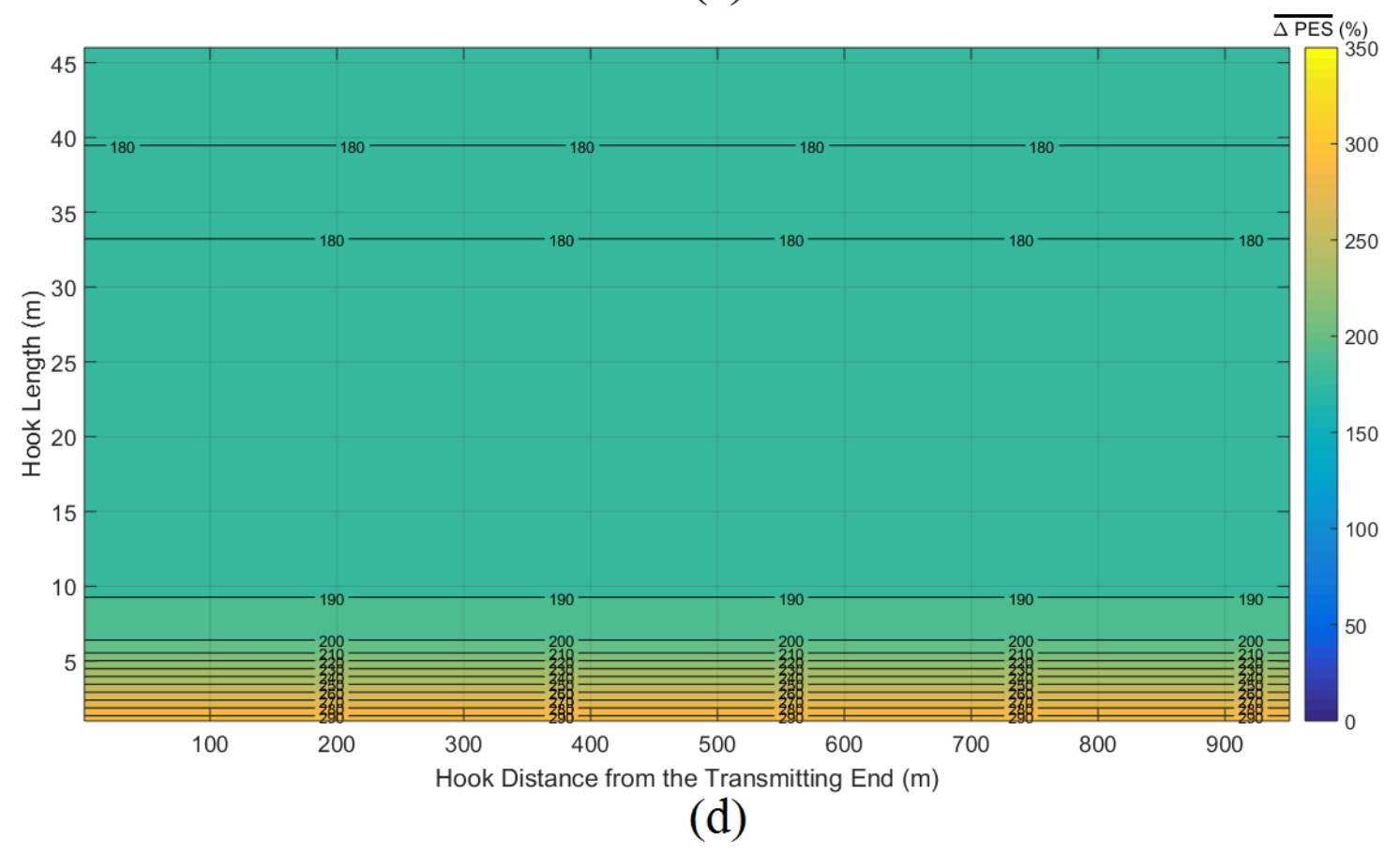




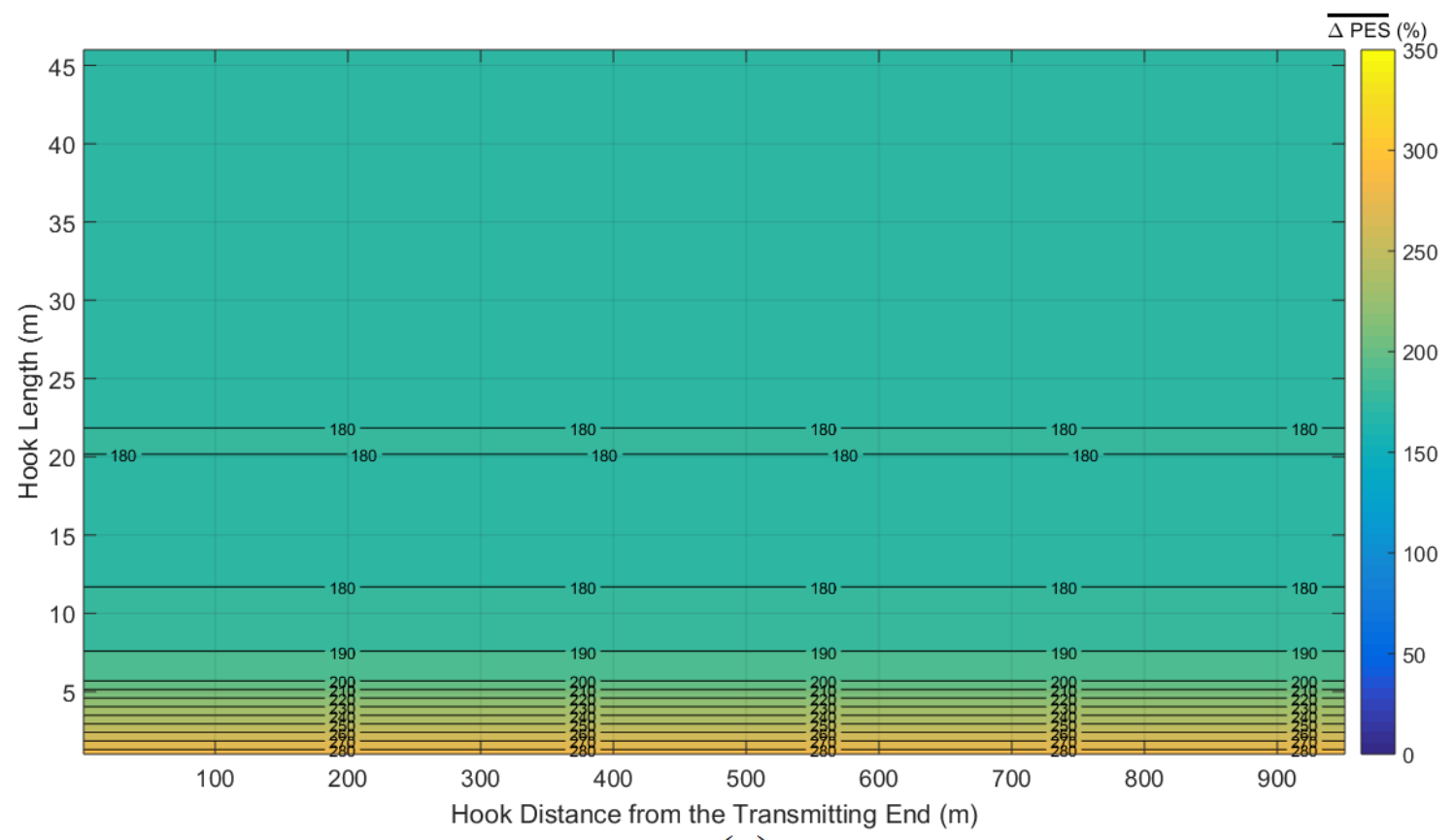

(e)

Fig. 8. Same curves with Fig. 4 but for the "LOS" case.

From Figs. 4-8, several interesting conclusions can be deduced concerning the performance of HS-DET method and its behavior when measurement differences of various maximum values $a_{\text {CUD }}$ are considered. More specifically:

- In general, measurement differences influence the values of $\overline{\triangle P E S}$ regardless of the examined OV LV BPL topology, the hook distance from the transmitting end and the hook length. Hence, the average $\overline{\triangle P E S}$ for given contour plot generally decreases with the increase of the maximum value $a_{\text {CUD }}$. This is shown through the adoption of colder colors in contour plots for given OV LV BPL topologies as the maximum value $a_{\text {CUD }}$ increases.

- The stochastic nature of measurement differences mainly affects OV LV BPL topologies with branches. Although the general morphology of $\overline{\triangle P E S}$ concerning the colored islands remains as the background image of contour plots, the impact of measurement differences on $\overline{\triangle P E S}$ acts additively to this image by creating new and frequent colored islands. Conversely, "LOS" topologies are not affected by the measurement differences on the basis of $\overline{\triangle P E S}$ since there is no creation of new colored islands in $\overline{\triangle P E S}$ contour plots.

- In the OV LV BPL topologies with branches, measurement differences further intensify the island effect of $\overline{\triangle P E S}$ at the transmitting and receiving end. In all the cases examined where the island effect occurs the islands remain regardless of the intensity of measurement differences.

- Also been observed in $\triangle P E S$, shorter hooks allow their easier identification by HS-DET method. In contrast, when the hooks are longer, $\triangle P E S$ and $\overline{\triangle P E S}$ values become significantly lower than the respective values for hooks with length being equal to $1 \mathrm{~m}$ for given OV LV BPL topology and maximum value $a_{\mathrm{CUD}}$. 
- HS-DET method can safely detect hook style energy thefts that may occur across the OV LV BPL networks. Safe decisions concerning the existence of energy theft or not can be made regardless of the examined OV LV BPL topology, the intensity of the measurement differences and the hook characteristics. $\triangle P E S$ and $\overline{\triangle P E S}$ maintain values greater than zero in all the cases examined. However, the issues that can be addressed regarding the future research are: (i) The existence / definition of the threshold of the maximum value $a_{\text {CUD }}$ above which HS-DET method starts to give faulty decisions concerning the energy theft (i.e., if / when $\triangle P E S$ and $\overline{\triangle P E S}$ can receive negative values); (ii) The possibility of the installation of very long hooks in order to mask the hook existence during the application of HS-DET method; and (iii) the use of "smart" hooks that are matched to the characteristic impedances of the lines in order again to camouflage the energy theft.

\section{Conclusions}

This paper has focused on the detection of the hook style energy theft in the OV LV BPL networks, which is a common type of energy theft in developing countries. Different OV LV BPL topologies, intensities of measurement differences and hook characteristics have been considered in order to assess the performance of the proposed HS-DET method. On the basis of $\triangle P E S$ and $\overline{\triangle P E S}$, several interesting conclusions have been deduced concerning the performance of HS-DET method. Initially, it has been revealed that the hook detection becomes easier in the cases of OV LV BPL topologies of low number of long branches such as "LOS" and rural OV LV BPL topologies. But the performance of HS-DET method mainly depends on the hook length; the detection of the hook style energy theft becomes easier when the hook remains short (i.e., shorter than $10 \mathrm{~m}$ ). As the influence of measurement differences is discussed, the stochastic nature of measurement differences mainly affects OV LV BPL topologies with branches. Although the general morphology of $\overline{\triangle P E S}$ contour plots remains the same, the increase of the CUD maximum value of measurement differences negatively influences the performance of HS-DET method. Anyway, HS-DET method successfully detected the energy theft in all the cases examined regardless of the CUD maximum value of measurement differences. Finally, due to the island effect that has been observed in $\triangle P E S$ and $\overline{\triangle P E S}$ contour plots, HS-DET method more easily detects the energy theft of hooks that are situated at the middle of the transmission path rather than near the transmitting and receiving ends. As the future research concerning the application of HS-DET method is discussed, there are three issues that need further analysis, namely: (i) the existence / definition of the threshold of the maximum value $a_{\text {CUD }}$ above which HS-DET method starts to give faulty decisions concerning the energy theft; (ii) the possibility of the installation of very long hooks so that HS-DET method can be jammed; and (iii) the use of "smart" hooks that are matched to the characteristic impedance of lines in order to cover the energy theft. 


\section{CONFLICTS OF INTEREST}

The author declares that there is no conflict of interests regarding the publication of this paper.

\section{References}

[1] C. H. Lo, and N. Ansari, "CONSUMER: A Novel Hybrid Intrusion Detection System for Distribution Networks in Smart Grid," IEEE Transactions on Emerging Topics in Computing, vol. 1, no. 1, pp. 33-44, 2013.

[2] R. Jiang, R. Lu, Y. Wang, J. Luo, C. Shen, and X. S. Shen, "Energy-theft Detection Issues for Advanced Metering Infrastructure in Smart Grid," Tsinghua Science and Technology, vol. 19, no. 2, pp. 105-120, 2014.

[3] P. Jokar, N. Arianpoo, and V. CM Leung, "Electricity Theft Detection in AMI Using Customers' Consumption Patterns," IEEE Transactions on Smart Grid, vol. 7, no. 1, pp. 216-226, 2016.

[4] S. Salinas, M. Li, and P. Li, "Privacy-preserving Energy Theft Detection in Smart Grids: A P2P Computing Approach," IEEE Journal on Selected Areas in Communications, vol. 31, no. 9, pp. 257-267, 2013.

[5] D. R. Pereira, M. A. Pazoti, L. A. Pereira, D. Rodrigues, C. O. Ramos, A. N. Souza, and J. P. Papa, "Social-Spider Optimization-based Support Vector Machines applied for energy theft detection," Computers \& Electrical Engineering, vol. 49, pp. 25-38, 2016.

[6] S. Salinas, M. Ming, and P. Li, "Privacy-preserving Energy Theft Detection in Smart Grids," Sensor, Mesh and Ad Hoc Communications and Networks (SECON), 2012, in proc. 9th Annual IEEE Communications Society Conference on. IEEE, pp. 605-613, 2012.

[7] S. McLaughlin, B. Holbert, S. Zonouz, and R. Berthier, "AMIDS: A Multi-sensor Energy Theft Detection Framework for Advanced Metering Infrastructures," in Smart Grid Communications (SmartGridComm), in proc of 2012 IEEE Third International Conference on, pp. 354-359, Nov. 2012.

[8] P. Antmann, "Reducing Technical and non-Technical Losses in the Power Sector," Background paper for the WBG Energy Strategy, Tech. Rep., Washington, DC, USA: The World Bank, 2009.

[9] P. McDaniel and S. McLaughlin, "Security and Privacy Challenges in the Smart Grid," IEEE Security \& Privacy, vol. 7, no. 3, pp. 75-77, 2009.

[10] Federal Court of Audit, "Operational Audit Report Held in National Agency of Electrical Energy, ANEEL, Brazil”, Rep. no. TC 025.619/2007-2, Brasília, Brazil, 2007.

[11] Ministry of Power, India, "Overview of power distribution," Tech. Rep., http://www.powermin.nic.in, 2013.

[12] C. Bandim, J. Alves, A. Pinto, F. Souza, M. Loureiro, C. Magalhges, and F. Galvez-Durand, "Identification of energy theft and tampered meters using a central observer meter: a mathematical approach," in Proc. Transmission Distrib. Conf. Exposition, Sep. 2003.

[13] A. Ruzzelli, C. Nicolas, A. Schoofs, and G. O'Hare, "Real-time recognition and profiling of appliances through a single electricity sensor," in Proc. IEEE SECON, June 2010. 
[14] E. L. Quinn, "Privacy and the new energy infrastructure," Social Science Research Netw., pp. 1995-2008, 2009 [Online]. Available: http://ssrn.com/paper=1370731

[15] "Privacy and the smart grid," NIST Guidelines for Smart Grid Cyber Security: vol.2, Aug. 2010 [Online]. Available: http://csrc.nist.gov/publications/nistir/ir7628/nistir-7628_vol1.pdf

[16] K. Sharma and L. M. Saini, "Power-line communications for smart grid: Progress, challenges, opportunities and status," Elsevier Renewable and Sustainable Energy Reviews, vol. 67, pp. 704-751, 2017.

[17] T. A. Papadopoulos, A. I. Chrysochos, A. ElSamadouny, N. Al-Dhahir, and G. K. Papagiannis, "MIMO-OFDM narrowband-PLC in distribution systems: Impact of power transformers on achievable data rates,". Elsevier Electric Power Systems Research, vol. 151, pp. 251-265, 2017.

[18] E. O. Kontis, T. A. Papadopoulos, A. I. Chrysochos, and G. K. Papagiannis, "Measurement-Based Dynamic Load Modeling Using the Vector Fitting Technique," IEEE Transactions on Power Systems, vol. 33, no. 1, pp. 338-351, 2018.

[19] A. G. Lazaropoulos, "Towards Modal Integration of Overhead and Underground Low-Voltage and Medium-Voltage Power Line Communication Channels in the Smart Grid Landscape: Model Expansion, Broadband Signal Transmission Characteristics, and Statistical Performance Metrics (Invited Paper)," ISRN Signal Processing, vol. 2012, Article ID 121628, pp. 1-17, 2012. [Online]. Available: http://www.hindawi.com/isrn/sp/2012/121628/

[20] A. G. Lazaropoulos, "Towards broadband over power lines systems integration: Transmission characteristics of underground low-voltage distribution power lines," Progress in Electromagnetics Research B, 39, pp. 89-114, 2012. [Online]. Available: http://www.jpier.org/PIERB/pierb39/05.12012409.pdf

[21] A. G. Lazaropoulos and P. G. Cottis, "Transmission characteristics of overhead medium voltage power line communication channels," IEEE Trans. Power Del., vol. 24, no. 3, pp. 1164-1173, Jul. 2009.

[22] A. G. Lazaropoulos and P. G. Cottis, "Capacity of overhead medium voltage power line communication channels," IEEE Trans. Power Del., vol. 25, no. 2, pp. 723 733, Apr. 2010.

[23] A. G. Lazaropoulos and P. G. Cottis, "Broadband transmission via underground medium-voltage power lines-Part I: transmission characteristics," IEEE Trans. Power Del., vol. 25, no. 4, pp. 2414-2424, Oct. 2010.

[24] A. G. Lazaropoulos and P. G. Cottis, "Broadband transmission via underground medium-voltage power lines-Part II: capacity," IEEE Trans. Power Del., vol. 25, no. 4, pp. 2425-2434, Oct. 2010.

[25] A. G. Lazaropoulos, "Broadband transmission characteristics of overhead highvoltage power line communication channels," Progress in Electromagnetics Research B, vol. 36, pp. 373-398, 2012. [Online]. Available: http://www.jpier.org/PIERB/pierb36/19.11091408.pdf

[26] A. G. Lazaropoulos, "Green Overhead and Underground Multiple-Input MultipleOutput Medium Voltage Broadband over Power Lines Networks: Energy-Efficient Power Control,'Springer Journal of Global Optimization, vol. 2012 / Print ISSN 0925-5001, pp. 1-28, Oct. 2012.

[27] A. G. Lazaropoulos, "Deployment Concepts for Overhead High Voltage Broadband over Power Lines Connections with Two-Hop Repeater System: Capacity 
Countermeasures against Aggravated Topologies and High Noise Environments," Progress in Electromagnetics Research B, vol. 44, pp. 283-307, 2012. [Online]. Available: http://www.jpier.org/PIERB/pierb44/13.12081104.pdf

[28] A. G. Lazaropoulos, "Broadband transmission and statistical performance properties of overhead high-voltage transmission networks,"HindawiJournal of Computer Networks and Commun., 2012, article ID 875632, 2012. [Online]. Available: http://www.hindawi.com/journals/jcnc/aip/875632/

[29] P. Amirshahi and M. Kavehrad, "High-frequency characteristics of overhead multiconductor power lines for broadband communications," IEEE J. Sel. Areas Commun., vol. 24, no. 7, pp. 1292-1303, Jul. 2006.

[30] T. Calliacoudas and F. Issa, "“Multiconductor transmission lines and cables solver," An efficient simulation tool for plc channel networks development," presented at the IEEE Int. Conf. Power Line Communications and Its Applications, Athens, Greece, Mar. 2002.

[31] T. Sartenaer and P. Delogne, "Deterministic modelling of the (Shielded) outdoor powerline channel based on the multiconductor transmission line equations," IEEE J. Sel. Areas Commun., vol. 24, no. 7, pp. 1277-1291, Jul. 2006.

[32] C. R. Paul, Analysis of Multiconductor Transmission Lines. New York: Wiley, 1994.

[33] H. Meng, S. Chen, Y. L. Guan, C. L. Law, P. L. So, E. Gunawan, and T. T. Lie, "Modeling of transfer characteristics for the broadband power line communication channel," IEEE Trans. Power Del., vol. 19, no. 3, pp. 1057-1064, Jul. 2004.

[34] B. Li, D. Mansson, and G. Yang, "An efficient method for solving frequency responses of power-line networks," Progress In Electromagnetics Research B, Vol. 62, 303-317, 2015. doi:10.2528/PIERB15013008 http://www.jpier.org/pierb/pier.php?paper $=15013008$

[35] M. Chaaban, K. El KhamlichiDrissi, and D. Poljak, "Analytical model for electromagnetic radiation by bare-wire structures," Progress In Electromagnetics Research B, Vol. 45, 395-413, 2012. doi:10.2528/PIERB12091102 http://www.jpier.org/pierb/pier.php?paper=12091102

[36] Y. H. Kim, S. Choi, S. C. Kim, and J. H. Lee, "Capacity of OFDM two-hop relaying systems for medium-voltage power-line access networks," IEEE Trans. Power Del., vol. 27, no. 2, pp. 886-894, Apr. 2012.

[37] A. G. Lazaropoulos, "Measurement Differences, Faults and Instabilities in Intelligent Energy Systems - Part 1: Identification of Overhead High-Voltage Broadband over Power Lines Network Topologies by Applying Topology Identification Methodology (TIM)," Trends in Renewable Energy, vol. 2, no. 3, pp. $85-112, \quad$ Oct. $2016 . \quad$ [Online]. Available: http://futureenergysp.com/index.php/tre/article/download/26/32

[38] A. G. Lazaropoulos, "Measurement Differences, Faults and Instabilities in Intelligent Energy Systems - Part 2: Fault and Instability Prediction in Overhead High-Voltage Broadband over Power Lines Networks by Applying Fault and Instability Identification Methodology (FIIM)," Trends in Renewable Energy, vol. 2, no. 3, pp. 113 - 142, Oct. 2016. [Online]. Available: http://futureenergysp.com/index.php/tre/article/view/27/33

[39] A. G. Lazaropoulos, "Power Systems Stability through Piecewise Monotonic Data Approximations - Part 2: Adaptive Number of Monotonic Sections and Performance of L1PMA, L2WPMA and L2CXCV in Overhead Medium-Voltage 
Broadband over Power Lines Networks," Trends in Renewable Energy, vol. 3, no. 1, pp. $33-60, \quad J a n . \quad 2017 . \quad$ [Online]. Available: http://futureenergysp.com/index.php/tre/article/view/30/35

[40] A. G. Lazaropoulos, "Power Systems Stability through Piecewise Monotonic Data Approximations - Part 1: Comparative Benchmarking of L1PMA, L2WPMA and L2CXCV in Overhead Medium-Voltage Broadband over Power Lines Networks," Trends in Renewable Energy, vol. 3, no. 1, pp. 2 - 32, Jan. 2017. [Online]. Available: http://futureenergysp.com/index.php/tre/article/view/29/34

[41] A. G. Lazaropoulos, "Main Line Fault Localization Methodology in Smart Grid Part 1: Extended TM2 Method for the Overhead Medium-Voltage Broadband over Power Lines Networks Case," Trends in Renewable Energy, vol. 3, no. 3, pp. 2-25, $\begin{array}{lll}\text { Dec. } 2017 . & \text { [Online]. }\end{array}$ http://futureenergysp.com/index.php/tre/article/view/36

[42] A. G. Lazaropoulos, "Main Line Fault Localization Methodology in Smart Grid Part 2: Extended TM2 Method, Measurement Differences and L1 Piecewise Monotonic Data Approximation for the Overhead Medium-Voltage Broadband over Power Lines Networks Case," Trends in Renewable Energy, vol. 3, no. 3, pp. 26-61, Dec. $2017 . \quad$ [Online]. Available: http://futureenergysp.com/index.php/tre/article/view/37

[43] A. G. Lazaropoulos, "Main Line Fault Localization Methodology in Smart Grid Part 3: Main Line Fault Localization Methodology (MLFLM)," Trends in Renewable Energy, vol. 3, no. 3, pp. 62-81, Dec. 2017. [Online]. Available: http://futureenergysp.com/index.php/tre/article/view/38

[44] A. G. Lazaropoulos, "Best L1 Piecewise Monotonic Data Approximation in Overhead and Underground Medium-Voltage and Low-Voltage Broadband over Power Lines Networks: Theoretical and Practical Transfer Function Determination," Hindawi Journal of Computational Engineering, vol. 2016, Article ID 6762390, 24 pages, 2016. doi:10.1155/2016/6762390. [Online]. Available: https://www.hindawi.com/journals/jcengi/2016/6762390/cta/

[45] A. G. Lazaropoulos, "Smart Energy and Spectral Efficiency (SE) of Distribution Broadband over Power Lines (BPL) Networks - Part 2: L1PMA, L2WPMA and L2CXCV for SE against Measurement Differences in Overhead Medium-Voltage BPL Networks," Trends in Renewable Energy, vol. 4, no. 2, pp. 185-212, Aug. $2018 . \quad$ [Online].

Available: http://futureenergysp.com/index.php/tre/article/view/77/pdf

[46] A. G. Lazaropoulos, "Smart Energy and Spectral Efficiency (SE) of Distribution Broadband over Power Lines (BPL) Networks - Part 1: The Impact of Measurement Differences on SE Metrics," Trends in Renewable Energy, vol. 4, no. 2, pp. 125-184, Aug. 2018. [Online]. Available: http://futureenergysp.com/index.php/tre/article/view/76/pdf

[47] P. Amirshahi and M. Kavehrad, "Medium voltage overhead powerline broadband communications; Transmission capacity and electromagnetic interference," in Proc. IEEE Int. Symp. Power Line Commun. Appl., Vancouver, BC, Canada, Apr. 2005, pp. 2-6.

[48] M. Tang, and M. Zhai, "Research of transmission parameters of four-conductor cables for power line communication," in Proc. Int. Conf. on Computer Science and Software Engineering, Wuhan, China, Dec. 2008, vol. 5, pp. 1306-1309. 
[49] M. D'Amore and M. S. Sarto, "A new formulation of lossy ground return parameters for transient analysis of multiconductor dissipative lines," IEEE Trans. Power Del., vol. 12, no. 1, pp. 303-314, Jan. 1997.

[50] M. D'Amore and M. S. Sarto, "Simulation models of a dissipative transmission line above a lossy ground for a wide-frequency range-Part I: Single conductor configuration," IEEE Trans. Electromagn. Compat., vol. 38, no. 2, pp. 127-138, May 1996.

[51] M. D'Amore and M. S. Sarto, "Simulation models of a dissipative transmission line above a lossy ground for a wide-frequency range-Part II: Multi-conductor configuration," IEEE Trans. Electromagn. Compat., vol. 38, no. 2, pp. 139-149, May 1996.

[52] N. Theethayi, "Electromagnetic interference in distributed outdoor electrical systems, with an emphasis on lightning interaction with electrified railway network," Ph.D. dissertation, Uppsala Univ., Uppsala, Sweden, Sep. 2005, [Online]. Available: http://uu.divaportal.org/smash/get/diva2:166746/FULLTEXT01

[53] A. G. Lazaropoulos, "Wireless Sensor Network Design for Transmission Line Monitoring, Metering and Controlling: Introducing Broadband over Power Linesenhanced Network Model (BPLeNM)," ISRN Power Engineering, vol. 2014, Article ID 894628, 22 pages, 2014. doi:10.1155/2014/894628. [Online]. Available: http://www.hindawi.com/journals/isrn.power.engineering/2014/894628/

[54] A. G. Lazaropoulos, "New Coupling Schemes for Distribution Broadband over Power Lines (BPL) Networks," Progress in Electromagnetics Research B, vol. 71, pp. 2016. 39-54, [Online]. Available: http://www.jpier.org/PIERB/pierb71/02.16081503.pdf

[55] A. G. Lazaropoulos, "Broadband Performance Metrics and Regression Approximations of the New Coupling Schemes for Distribution Broadband over Power Lines (BPL) Networks," Trends in Renewable Energy, vol. 4, no. 1, pp. 43 73, 2018. [Online]. Available: http://www.futureenergysp.com/index.php/tre/article/view/59/pdf

[56] OPERA1, D44: Report presenting the architecture of plc system, the electricity network topologies, the operating modes and the equipment over which PLC access system will be installed, IST Integr. Project No 507667, Dec. 2005.

[57] OPERA1, D5: Pathloss as a function of frequency, distance and network topology for various LV and MV European powerline networks. IST Integrated Project No 507667, Apr. 2005.

[58] A. G. Lazaropoulos, "Factors Influencing Broadband Transmission Characteristics of Underground Low-Voltage Distribution Networks,'IET Commun., vol. 6, no. 17, pp. 2886-2893, Nov. 2012.

[59] J. Anatory, N. Theethayi, and R. Thottappillil, "Power-line communication channel model for interconnected networks-Part II: Multiconductor system," IEEE Trans. Power Del., vol. 24, no. 1, pp. 124-128, Jan. 2009.

[60] J. Anatory, N. Theethayi, R. Thottappillil, M. M. Kissaka, and N. H. Mvungi, "The effects of load impedance, line length, and branches in typical low-voltage channels of the BPLC systems of developing countries: transmission-line analyses," IEEE Trans. Power Del., vol. 24, no. 2, pp. 621-629, Apr. 2009.

[61] A. G. Lazaropoulos, "A Panacea to Inherent BPL Technology Deficiencies by Deploying Broadband over Power Lines (BPL) Connections with Multi-Hop 
Repeater Systems," Bentham Recent Advances in Electrical \& Electronic Engineering, vol. 10, no. 1, pp. 30-46, 2017.

[62] A. G. Lazaropoulos, "Improvement of Power Systems Stability by Applying Topology Identification Methodology (TIM) and Fault and Instability Identification Methodology (FIIM) - Study of the Overhead Medium-Voltage Broadband over Power Lines (OV MV BPL) Networks Case," Trends in Renewable Energy, vol. 3, no. 2, pp. 102-128, Apr. 2017. [Online]. Available: http://futureenergysp.com/index.php/tre/article/view/34

Article copyright: (C) 2019 Athanasios G. Lazaropoulos. This is an open access article distributed under the terms of the Creative Commons Attribution 4.0 International License, which permits unrestricted use and distribution provided the original author and source are credited. 